\title{
Nueva propuesta sobre la simbología de la diadema del tesoro de Ébora
}

\author{
New proposal on the symbology of the diadem of the \\ Ebora's treasure
}

\author{
Álvaro Gómez Peña \\ Universidad de Sevilla
}

\section{RESUMEN}

En el presente estudio se realiza una nueva interpretación sobre el significado de las piezas que componen la zona central de la diadema del tesoro de Ébora. En concreto se defiende que el conjunto está formado por las representaciones de un altar con forma de piel de toro, una asherah, una massebah y una figura antropomorfa que podría tratarse de una representación del dios Bes o de un héroe/divinidad naciendo de la roca. Dichos elementos, especialmente los tres primeros, pueden encontrarse en varios santuarios de tradición fenicio-púnica dentro de la Península Ibérica, la misma identidad que podría otorgársele a la diadema de Ébora. Con esta propuesta se pretende generar una hipótesis simbólicamente más homogénea que las que han ofrecido anteriores publicaciones sobre esta pieza.

\section{SUMMARY}

In the present study a new interpretation about the symbology of the central elements of the diadem of the Ebora's treasure is performed. Concretely, it is proposed that the set consists of representations of a bull's hide altar, an asherah, a massebah and an anthropomorphic figure that could be a representation of the god Bes or a hero/deity born of the rock. These elements, especially the first three, can be found in some sanctuaries of Phoenician-Punic tradition in the Iberian Peninsula, the same identity that could be granted to the diadem of Ebora. This proposal is intended to create a more homogeneous hypothesis than the previous ones published.

PALABRAS CLAVE: Sanlúcar de Barrameda; altar taurodérmico; asherah; massebah; figura antropomorfa.

KEY WORDS: Sanlucar de Barrameda; bull's hide altar; asherah; massebah; anthropomorphic figure.

CÓMO CITAR ESTE ARTÍCULO / CITATION: Gómez Peña, Á. 2018: "Nueva propuesta sobre la simbología de la diadema del tesoro de Ébora". Archivo Español de Arqueología 91: 67-88. https://doi.org/10.3989/aespa.091.018.004

\footnotetext{
1 agomez19@us.es / ORCID iD: https://orcid.org/00000002-2926-5243.
}

\section{INTRODUCCIÓN}

El 23 de noviembre de 1958, Francisco Bejarano Ruiz, Paquito, el hijo del vaquero mayor del cortijo de Ébora (Sanlúcar de Barrameda, Cádiz), encontraba varias piezas de oro sobre el terreno recién arado mientras paseaba a una piara de cerdos a unos 30 $\mathrm{m}$ al norte de la casa de la finca (Fig. 1). Tras las vicisitudes que suelen acompañar a este tipo de hallazgos fortuitos se informó a la Guardia Civil sobre su descubrimiento. Al poco tiempo, Carriazo decidió realizar excavaciones en el lugar del hallazgo, localizándose algunas pequeñas piezas de oro en el corte abierto, así como también durante el cribado de la tierra extraída. Se observó que estas formaban parte del conjunto ya encontrado, lo que confirmaba el hecho de estar ante el lugar del hallazgo. Sin embargo, a pesar de las esperanzas puestas en los descubrimientos de los primeros días, la campaña tan sólo dio con un silo de época imprecisa, algunos muros destruidos y cerámicas de filiación púnica y romana que no aportaron luz sobre el contexto exacto de las joyas (Carriazo 1973).

La falta de un contexto claro en el que insertar el tesoro de Ébora no es una exclusividad de su hallazgo. Se trata de una constante en el descubrimiento del resto de diademas documentadas en la Península Ibérica (Perea 2006). Casual fue el hallazgo de la de Jávea (Alicante) dentro de un jarro cerámico no conservado. Del mercado de antigüedades procede el ejemplar de La Puebla de los Infantes (Sevilla) que se encuentra expuesto en el Museo Arqueológico Nacional. Tampoco se conocen los datos contextuales de la diadema de Mairena del Alcor (Sevilla), depositada en el Museo Arqueológico de Sevilla. Cues- 


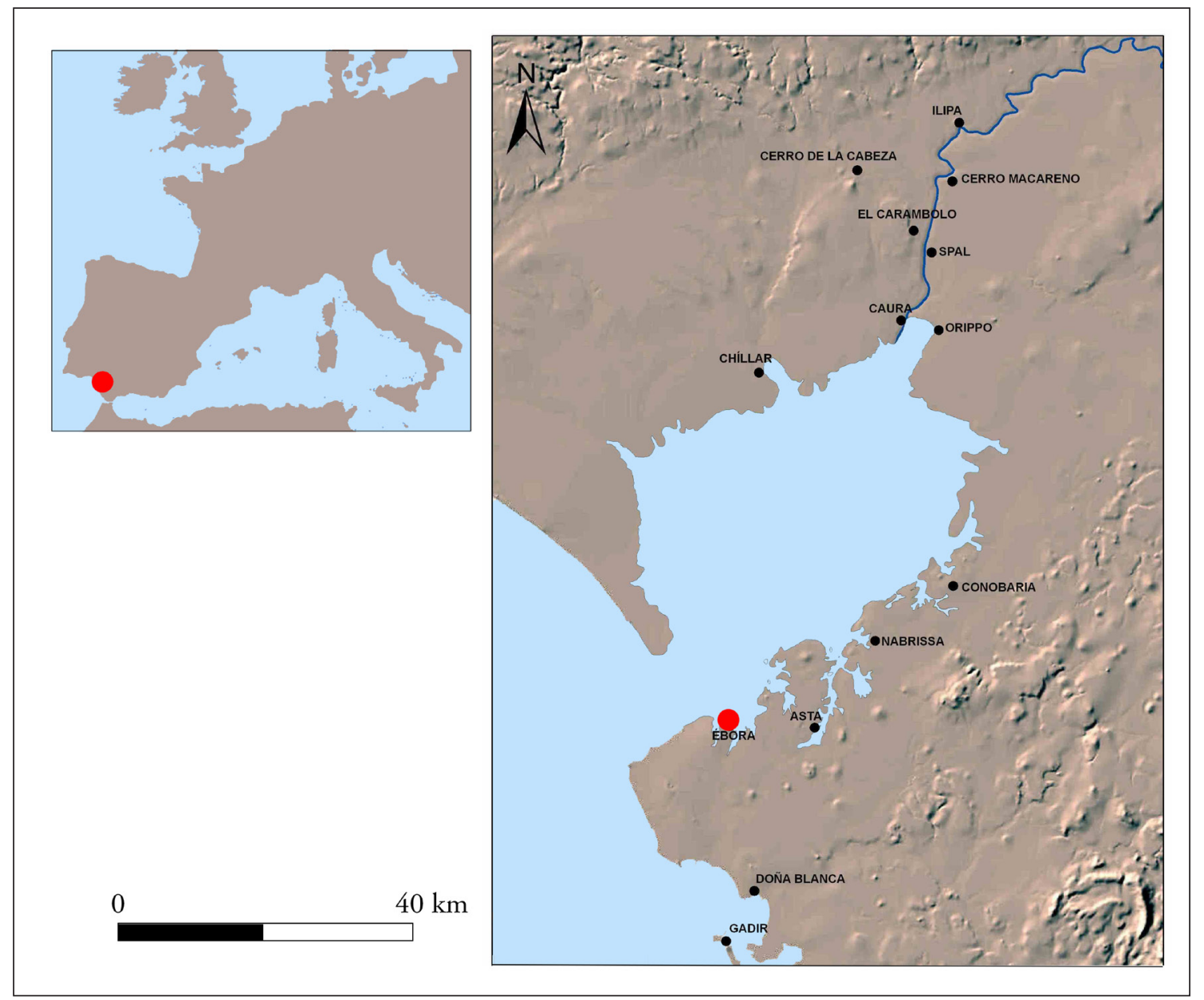

Figura 1. Mapa con la localización de Ébora en la paleotopografía del Lacus Ligustinus.

tión similar ocurría hasta hace escasos años con el tesoro de Aliseda (Cáceres), cuyo contexto ha sido largamente debatido y cuenta con recientes revisiones historiográficas de indudable interés (Celestino y Salgado 2007; Rodríguez Díaz et alii 2014; Pavón et alii 2017; Rodríguez Díaz et alii 2017). En este último caso, junto al conjunto áureo aparecieron un brasero de plata, un jarro de vidrio y una pátera de oro, lo que ha llevado tradicionalmente a los investigadores a suponer un origen funerario para las piezas (Almagro Gorbea 1977: 204 y ss.), cuestión que ha sido rebatida con interesantes argumentos a partir de los últimos datos conocidos sobre su posible lugar de aparición (Rodríguez Díaz et alii 2017).

El tesoro de Ébora consta de 93 piezas de oro y 43 de cornalina halladas en tres lotes diferentes. El primero fue localizado por Paquito. El segundo se formó a partir de varias piezas encontradas días después en las inmediaciones del lugar del hallazgo y por otras que se habían escondido en el garaje de la finca. El último conjunto se encontró en las excavaciones realizadas por el propio Carriazo. De entre todas sus joyas el interés del presente estudio se centra en una posible diadema articulada de extremos triangulares (Torres 2002: 239-240). La de Ébora se encuentra formada por un triángulo en cada uno de sus laterales decorado con dos SS opuestas y una pareja de cuadrúpedos de cara a una palmeta central que podría representar al árbol de la vida adorado por bestias o a la flor de la eterna juventud protegida por animales de carácter sagrado. Ambos triángulos están conectados a través de cuatro hileras: 1) piezas de tendencia rectangular que constan de un cuerpo central con cuatro líneas granuladas paralelas y junto a él una pequeña esfera a cada lado; 2) columnas con decoración en zigzag en sus laterales; 3) dos lengüetas verticales sobre un pequeño rectángulo con un aspa y 4) figuras antropomorfas (Fig. 2). 


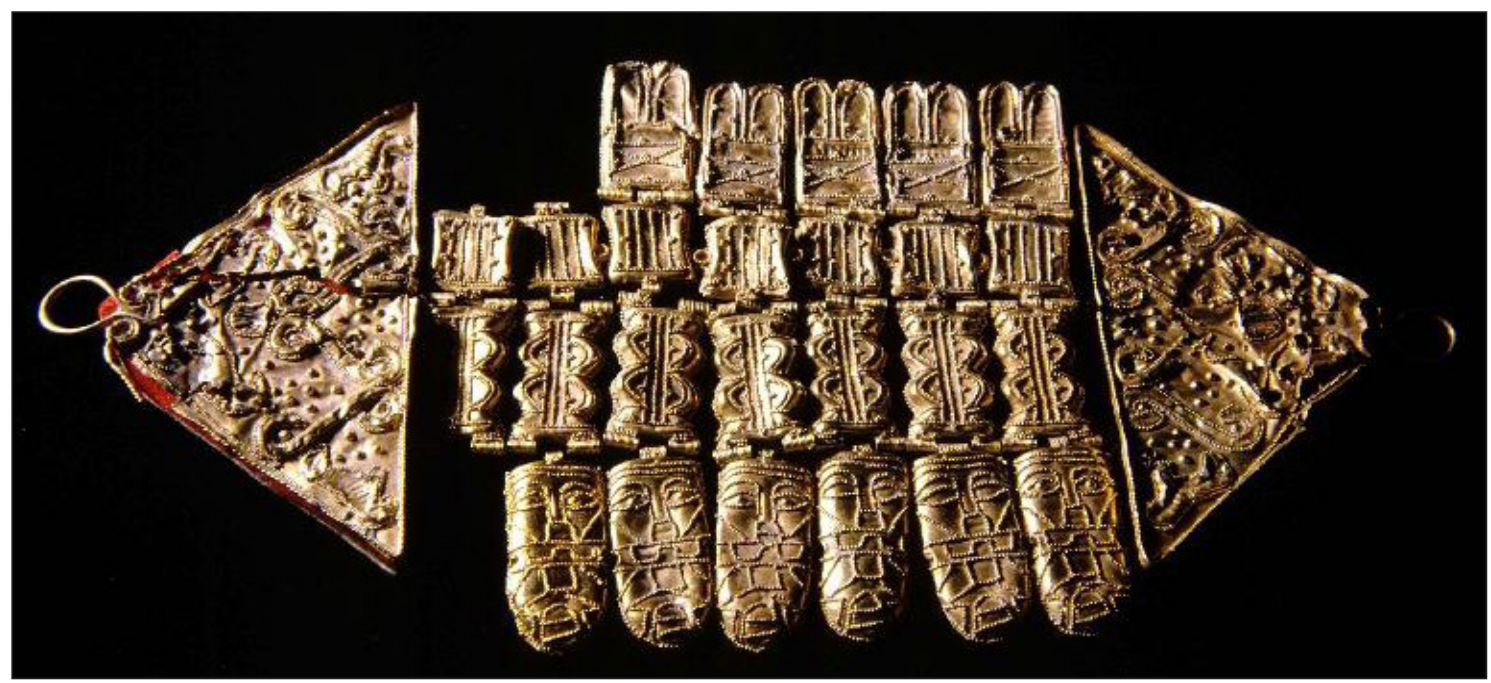

Figura 2. Diadema del tesoro de Ébora.

En las siguientes páginas se prestará especial atención a las propuestas que se han realizado desde su descubrimiento hasta la actualidad a propósito de su simbología para acabar profundizando en el posible significado de sus representaciones con una nueva hipótesis de trabajo.

\section{PROPUESTAS PLANTEADAS SOBRE SU SIM- BOLOGÍA}

La primera de las propuestas sobre la simbología de la diadema del tesoro de Ébora fue publicada por Blanco de Torrecillas, a quien siguió Carriazo en sus hipótesis. Para aquél, los dos primeros elementos acabados de describir no tenían una interpretación clara. Con respecto al tercero, barajó la posibilidad de que se tratase de un díptico al estilo de las Tablas de la Ley dado que una de las piezas muestra posibles líneas de escritura. Mayor juego le ofrecía el último elemento ya que su mitad superior fue interpretada como una cara barbuda — con el cercano paralelo de la máscara de Tharsis-, mientras que en cuanto a la inferior, en una primera publicación se sugirió que podría tratarse de un elefante o un aderezo (Blanco 1959: 14-15). Con el paso de los años, Carriazo cambió su opinión sobre esta última propuesta al pensar que se trataría de las piernas de un Bes estilizado (Carriazo 1973: 344-345). Posiblemente en dicho cambio influyera la idea de Maluquer, para quien la parte inferior de este último motivo se trataría de un faldellín acampanado (Maluquer 1958: 210).

Por su parte, Nicolini publicó años después que no encontraba claros paralelos para los dos primeros elementos del conjunto, mientras que el cuarto sería un Bes o Her púnico sobre un uraeus y un montículo, y el tercero la corona de plumas de Bes o el tocado que en ocasiones lleva Baal (Nicolini 1990: 486).

También Fernández Gómez ha tratado brevemente el significado de las piezas de la posible diadema de Ébora. Para las dos primeras imágenes no se propone ningún paralelo simbólico, sino que se plantea que pudiera tratarse de meras decoraciones geométricas. Por su parte, para las dos últimas baraja la posibilidad de que se trate de una figura masculina de grandes ojos y una tiara o corona alta. En concreto, se trataría de una imagen que habría tratado de representar un personaje al estilo de los ídolos oculados calcolíticos. En último lugar, los triángulos dejarían ver el árbol de la vida entre animales (Fernández Gómez 1997: 61-62).

La más reciente de las interpretaciones ha sido la propuesta por Perea. Para esta autora, siguiendo la hipótesis de Celestino (1994), el primer elemento tendría forma de lingote chipriota/piel de bóvido. El segundo reflejaría dos betilos reproduciendo el fuste estriado de los 'candelabros de Lebrija'. La figura antropomorfa no sería otra cosa que la imagen de una diosa alada de pechos desnudos con un rostro enorme con respecto al resto del cuerpo. Finalmente, a propósito de la pieza interpretada como un díptico con escritura por Blanco y Carriazo, Perea no se pronuncia. A partir de todo el conjunto, las placas le sugieren una lectura relacionada con el espacio de la diosa en el entorno sacro del santuario que la guarda (Perea 2007: 205).

Viendo en perspectiva todas estas propuestas, no existe un patrón que se repita en todas ellas. En unas 


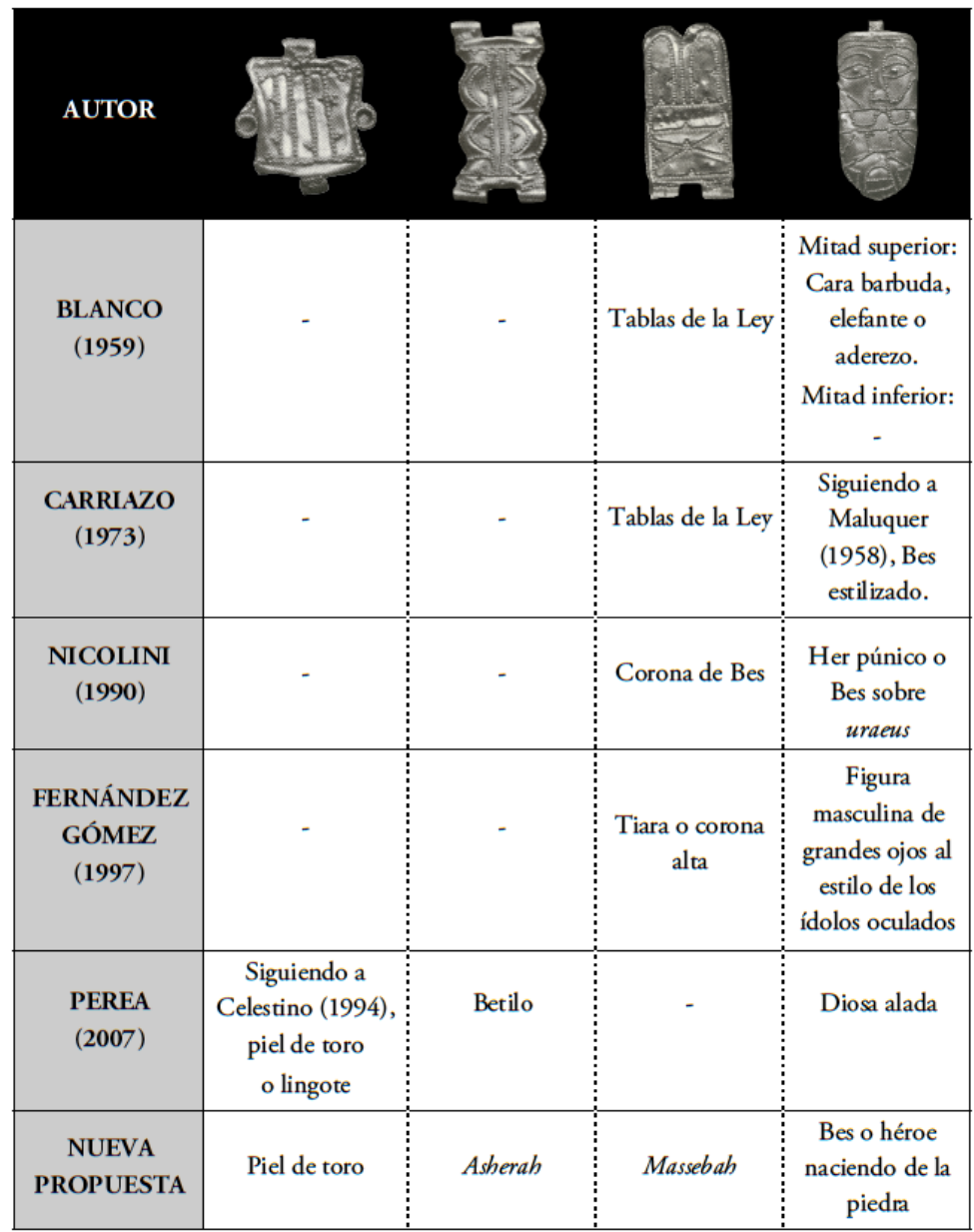

Figura 3. Propuestas interpretativas sobre la simbología de las piezas de la diadema del tesoro de Ébora.

ocasiones el primero y el segundo de los elementos no son reconocidos con ningún objeto en concreto, mientras que en otras son tenidos por simples formas geométricas. En otros casos se piensa que puede tratarse de pieles de toro y betilos, contando con el inconveniente en estos casos de que se dejan sin explicación otras piezas o la totalidad del conjunto carece de una homogeneidad interpretativa. Cuando esto ocurre se da la sensación de que los cuatro elementos engarzados en sucesivas hileras pudieron haber guardado quizás una relación emocional con su portadora, pero no una coherencia interna como partes interconectadas de un lenguaje simbólico visible para cualquier espectador.

Desde un punto de vista instrumentalista, la alternativa ofrecida debería dar respuesta a todas y cada una de las piezas presentes en la diadema con mayor coherencia tanto interna como externa entre sus partes.
Tratando de solucionar estos problemas se propone una nueva hipótesis de trabajo.

\section{NUEVA INTERPRETACIÓN}

En el presente estudio se propone analizar la posible diadema de Ébora desde el punto de vista de la tradición religiosa fenicia. Desde esta perspectiva, los cuatro elementos centrales estarían reflejando un altar taurodérmico, una asherah o árbol sagrado próximooriental, una massebah o betilo díptico que albergaría a las divinidades fenicias y una figura antropomorfa de dudosa identidad que podría representar a Bes o a una divinidad naciendo de una piedra betílica, pero sobre la que estamos abiertos a nuevas interpretaciones. A estos elementos habría que sumar la escena de los triángulos laterales en los que aparecen animales 
custodiando una palmeta sagrada que simbolizaría el árbol de la vida o la flor del rejuvenecimiento, la misma que se protege en la fuente de bronce de El Gandul o la misma que apareció en la tumba 20 de Galera. Se trata de otro símbolo de clara tradición oriental que cuenta con numerosos paralelos dentro del mundo fenicio, tanto en el Mediterráneo Oriental como en la Península Ibérica (Blázquez 1956; Almagro-Gorbea y Torres 2011: 245 y ss.).

Con respecto a los primeros, son numerosas las referencias bíblicas que hacen alusión a una tríada de elementos cultuales propios de las poblaciones cananeas contrarias a los intereses hebreos. Se trata del altar, la asherah y la massebah, sobre los que en la Biblia se recogen en varias ocasiones exhortaciones realizadas hacia el pueblo israelí para que destruyera las aras fenicias, derribase sus masseboth y cortase sus asherim (Deut. 7:5; Deut. 16:21-22; 1 Reyes 14:2223) (Fig. 3). En los siguientes epígrafes se recogerán sucintamente las características de estos objetos y los datos que me hacen proponer su presencia en la posible diadema de Ébora.

\subsection{Altar CON FORMA DE PIEL DE TORO}

El descubrimiento en 1958 del tesoro de El Carambolo no sólo dio origen a la moderna arqueología tartésica, sino que además supuso el inicio de la tradición historiográfica sobre la forma que se analiza en este epígrafe. Al buscar paralelos para la forma de los dos pectorales, Kukahn y Blanco propusieron una buena muestra de elementos con similar perfil procedentes del Mediterráneo oriental:

Como motivo ornamental se encuentra en vasos micénicos, en los tableros de marfil, para juego, de Megiddo, en las pinturas de los palacios asirios y sirios de Khorsabad, Arslan-Tash, Tel-Barsib, etc., e incluso en lingotes de cobre de la época premonetal que aspiran a reproducir la piel extendida de un buey (Kukahn y Blanco 1959: 42).

Con dichas palabras se introducían en la literatura específica española los dos grandes referentes hasta el presente para buscar el origen de la forma aquí analizada: la forma de la piel extendida de un bóvido y la de unos peculiares lingotes de cobre aparecidos por todo el Mediterráneo e incluso el Atlántico y Europa Central. En esta búsqueda de paralelos para los 'pectorales', Kukahn y Blanco se decantaron por considerar que la forma de los lingotes estaba en realidad basada en el perfil que presentan las pieles bovinas tras su desuello y perfilado. Sin embargo, pocos años después la influyente figura de Maluquer (1984 [1970]: 117-118) propuso relacionar directamente estas piezas con los propios lingotes, y por extensión con las ricas minas tartésicas: "Los grandes pectorales, en realidad, no sabemos cómo se llevarían. $\mathrm{Su}$ forma es ciertamente la de los lingotes o galápagos de metal" (Maluquer 1984 [1970]: 135)².

A estas interpretaciones le sucedió el hallazgo de la fuente de bronce forjado encontrada en la tumba 16 de la necrópolis de La Joya. La forma y el material metálico en que estaba facturada dicha bandeja llevó a sus descubridores a proponer como referente directo una vez más los propios lingotes (Garrido y Orta 1978: 49). Al igual que Maluquer, estos autores se decantaban por una opción y silenciaban otra, quizás dejándose llevar por la similitud visual que ofrecían ambos objetos, los cuales tenían la filiación chipriota con la que los autores de las excavaciones de La Joya vincularon muchas de las piezas aparecidas en el interior de sus tumbas (Garrido y Orta 1978).

Tan sólo con posterioridad, tras los hallazgos de los altares de Cancho Roano (Zalamea de la Serena, Badajoz) y de Caura (Coria del Río, Sevilla) se empezó a valorar la simbología taurodérmica como auténtico leitmotiv de estos objetos. En este sentido hay que destacar la figura de Escacena, quien como director de las excavaciones del yacimiento de Caura interpretó el ara allí aparecida como el trasunto de una piel de toro tanto por sus características formales, como por las cromáticas y las simbólicas. Para él, el altar del municipio sevillano presenta la característica forma taurodérmica tras su procesado artesanal, mostrando una línea interna paralela a su contorno exterior, haciendo alusión al modo en que el pelo de las bestias era recortado. Así se presenta la parte interior de un color rojizo propio del pelaje de animales castaños, mientras la exterior fue decorada con tonos amarillentos dada la coloración que presenta el pellejo depilado del animal. A su vez, la fase más antigua del altar - fase A - tenía un receptáculo para recoger líquidos que estaría imitando al cuello del animal. Apoyando esta idea, las monturas de varias piezas votivas procedentes de El Cigarralejo (Murcia) y de la yegua de bronce igualmente votiva del santuario de Cancho Roano muestran el mismo perfil (Escacena 2000: 177-184) (Fig. 4).

Así las cosas, desde finales de los años noventa del pasado siglo, el número de objetos que ha sido relacionado con una u otra forma dentro de la protohistoria peninsular ibérica ha ido creciendo de manera

\footnotetext{
${ }^{2}$ Opinión también defendida por aquellas fechas a propósito de algunos símbolos de las estelas del suroeste por M. Bendala (1977).
} 


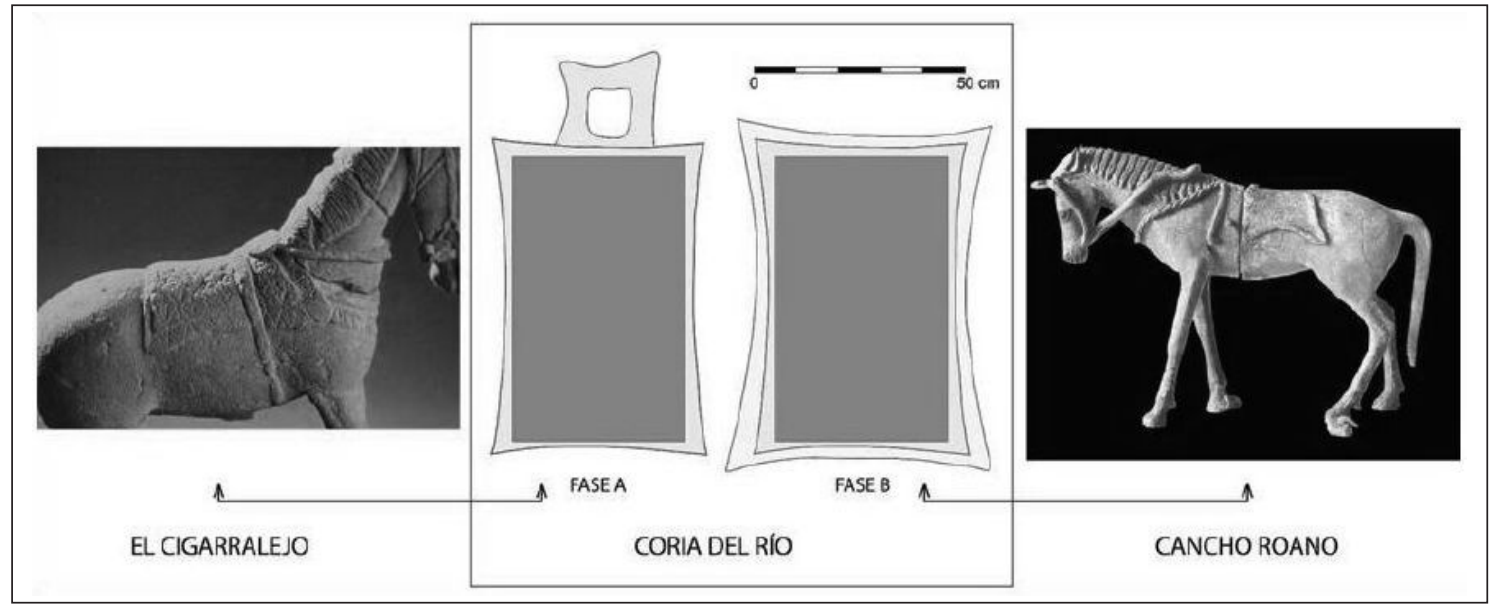

Figura 4. Altares de las fases A y B de Caura. El primero muestra un receptáculo para libaciones y otros líquidos simulando el cuello que conservaban algunas pieles como se observa en la lengüeta vuelta hacia atrás en la pieza de El Cigarralejo (Mula, Murcia). Por su parte, el ara B es más esquemática y recuerda más en su forma a la montura de la yegua de Cancho Roano (Escacena y Coto 2010: 159).

casi exponencial, no sólo en cuantía sino también en importancia dentro de la historiografía. Tanto es así que desde los años noventa se les ha dedicado diversos estudios, en parte o en su totalidad, en los que se sigue como tónica general dar una visión de conjunto de todos y cada uno de los ejemplares con diferentes conclusiones y siempre en clara conexión con piezas orientales (Celestino 1994; 2008; Lagarce y Lagarce 1997; Escacena e Izquierdo 2000; Escacena 2002; 2006; 2007; 2011; Amores y Escacena 2003; Escacena y Coto 2010; Escacena y Amores 2011; Maier 2003; López Pardo 2006; Marín 2006; Vázquez Hoys 2006; Gómez Peña 2010; 2011; 2012-2013; Almagro-Gorbea y Lorrio 2011; Almagro-Gorbea et alii 2011-2012; Tejera y Fernández 2012).

Por lo que respecta a la diadema de Ébora, las primeras interpretaciones en las que se propuso que las piezas rectangulares podrían ser lingotes/pieles fueron realizadas por Celestino y Blanco (Celestino 1994; Blanco y Celestino 1998: 73). La forma representada en ella muestra los laterales ligeramente rehundidos hacia el interior, forma que se observa en algunos lingotes de tradición sirio-chipriota. A cada lado, un círculo acompaña a esta figura. Una primera interpretación podría sugerir que esta circunferencia estaría haciendo las veces del cuello del animal, que en ejemplares como el de Caura sirve de receptáculo donde se habrían vertido algunos líquidos durante los rituales realizados sobre el altar. Sin embargo, estos círculos aparecen en el ejemplar de Ébora en sus laterales, mientras que en las aras el receptáculo está siempre en uno de sus extremos cortos, lo que aconseja desechar esta hipótesis.
Debido a este dato se propone paralelizar estos círculos con los que se observan en algunos cilindrossellos chipriotas, donde aparecen en ocasiones dos circunferencias a los lados de las aras. En una publicación previa se ha propuesto que estos elementos podrían ser representaciones de la divinidad como astro solar, pues en un ejemplar aparece el mismo elemento sobre el altar envuelto en llamas como posible símbolo de la egersis de la deidad (Gómez Peña 2010: 138) (Fig. 5).

\subsection{ASHERAH}

En cuanto a la asherah, la arqueología que se ha venido centrando en el Próximo Oriente y el Mediterráneo Oriental se ha ocupado en varias ocasiones de manera monográfica del culto a ésta y de sus diversas manifestaciones (Binger 1997; Merlo 1998; Hadley 2003; Cornelius 2004). Un repaso por ellas muestra que las referencias a la diosa Asherah en Ugarit, Mesopotamia, Palestina y el Antiguo Testamento son exclusivamente textuales, por lo que a partir de estos casos no es posible poner imagen a esta divinidad (Merlo 1998: 225). Para paliar este problema, los investigadores que han tratado de identificar a Asherah se han venido posicionando dentro de dos corrientes principales. De una parte están quienes han considerado que el término asherah que aparece en la Biblia no se trataría de una deidad, sino de un mero elemento arqueológico, bien una simple imagen de madera que habría recibido culto, una arboleda o un árbol vivo. De otra quienes además de considerarlo 


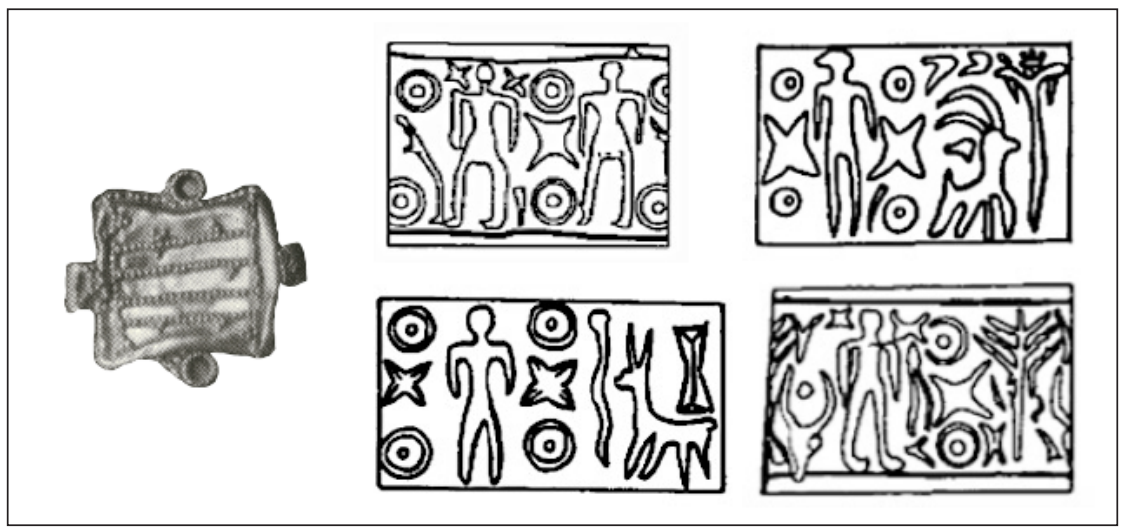

Figura 5. Izquierda) Altar taurodérmico. Derecha) Diversos cilindros-sellos chipriotas donde se ha representado una de estas aras con sendos soliformes a cada lado.

como tal, piensan que bajo ese apelativo también se encuentra una divinidad específica que suele aparecer desnuda de frente al espectador (Hadley 2003: 4-37).

Entre medias de esta discusión, dos hitos principales han jalonado la investigación durante décadas. El primero de ellos, el descubrimiento de los textos ugaríticos en 1929 en los que se puede leer el término Asherah como apelativo de una divinidad femenina, lo que daba otra dimensión al empleo atestiguado en la Biblia. De otra parte, el hallazgo de la inscripción de Khirbet el-Qom y los dibujos de inscripciones de Kuntillet 'Ajrud, tratado posteriormente a propósito de la figura antropomorfa que presenta la posible diadema de Ébora.

Dentro de la tradición cananea, Asherah aparece ya como diosa en Ugarit desde el II milenio a. C., así como en el panteón tirio en la Épica de Keret datada entre 1500-1200 a. C. (Hadley 2003: 41-43). Sin embargo, para el caso particular que aquí me ocupa, la información más interesante procede de las referencias bíblicas antes indicadas. En la inmensa mayoría de estas menciones se hace alusión a un objeto de madera sin apelar a una divinidad en cuestión (Hadley 2003: 54-83). En varios de los pasajes se pide que se corten, a la vez que se destruyan los altares y las masseboth. Estos datos cuadran con la posibilidad de que las asherim fuesen postes de madera, de los que se disponen posibles huellas con restos cenicientos donde hincarlos muy cerca de los altares taurodérmicos en santuarios como el de El Carambolo y Caura, así como en diversas representaciones propias de la eboraria tartésica (Escacena 2013: 173).

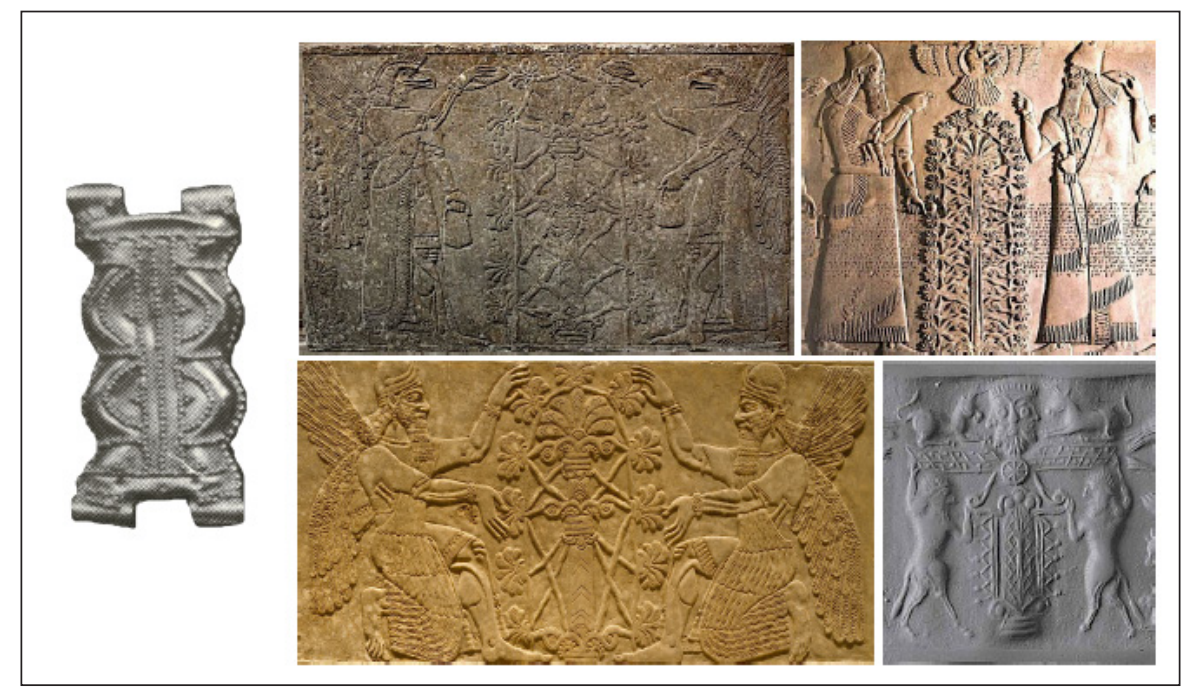

Figura 6. Izquierda) Asherah. Derecha) Diversas representaciones próximo-orientales en las que se observan árboles de la vida con decoración en zig-zag. 
Con estos antecedentes y paralelos dentro del mundo cananeo, a los que hay que sumar las numerosas representaciones en cilindros-sellos chipriotas ya publicadas y analizadas en estudios anteriores (Gómez Peña 2010; 2011), la propuesta que aquí se realiza es tener por una asherah el segundo de los elementos de la decoración central de la diadema de Ébora. De estar en lo correcto, el fuste central de esta pieza se correspondería con el poste de madera, mientras que las líneas en zig-zag de sus lados serían representaciones de las ramas y brotes, tal y como se observa en diferentes imágenes de árboles de la vida procedentes del Mediterráneo Oriental y el Próximo Oriente asiático (Fig. 6).

\subsection{MASSEBAH}

En tercer lugar se encuentra la pieza que ha sido tenida en otras interpretaciones por las Tablas de la Ley o la corona de Bes y que aquí se relaciona con las masseboth orientales. Resulta sorprendente la escasa atención dedicada a estos objetos tanto en el Mediterráneo Oriental como en el territorio tartésico. De entre lo poco que se sabe sobre este tipo de elementos, puede afirmarse que la massebah se compone de una o varias piedras sobre una plataforma elevada del suelo que presenta un carácter polisémico. Entre sus posibles usos se encuentra el de morada de la divinidad, destacando el carácter anicónico de la misma. Sin embargo, también pudo haber funcionado como estela. Incluso a partir de la epigrafía púnica se le puede considerar como топиmentum en tanto en cuanto reclama la atención del caminante que lo observa (Seco 2010: 49). Al hilo de esta polisemia indicada, Seco ha propuesto con buen criterio que no todas las masseboth habrían sido betilos, ni todos los betilos habrían sido masseboth (Seco 2010: 49).

Por lo que respecta a la dispersión geográfica de estas piedras, el Mediterráneo Oriental cuenta con un buen número de casos bien documentados (Mettinger 1995: 143-191), tanto individualmente como por parejas, triadas e incluso en grupos de cinco, siete y nueve ejemplares. De especial importancia para el caso que aquí se analiza son las famosas Piedras Tirias o Piedras Ambrosiales (Nonn. D. XL, 465-477) en compañía de un olivo sagrado (Bijovsky 2005). A propósito de ellas destacan las acuñaciones de Gordiano, Treboniano Galo, Valeriano, Heliogábalo, Aquilia Severa, Julia Mesa, Volusiano y Galieno (Seco 2010: 106). Este binomio árbol-massebah suele repetirse en diversos momentos de la antigüedad, por lo que no habría que descartar que la asherah participase de esta misma idea.

Con estos antecedentes y conexiones cultuales dentro de la tradición cananea, la tercera de las piezas que compone el conjunto de Ébora cobra coherencia interna con respecto al resto del conjunto. En este caso, las dos lengüetas interpretadas por algunos autores como las plumas de la corona de Bes serían dos masseboth de piedra con indicios de posible escritura,

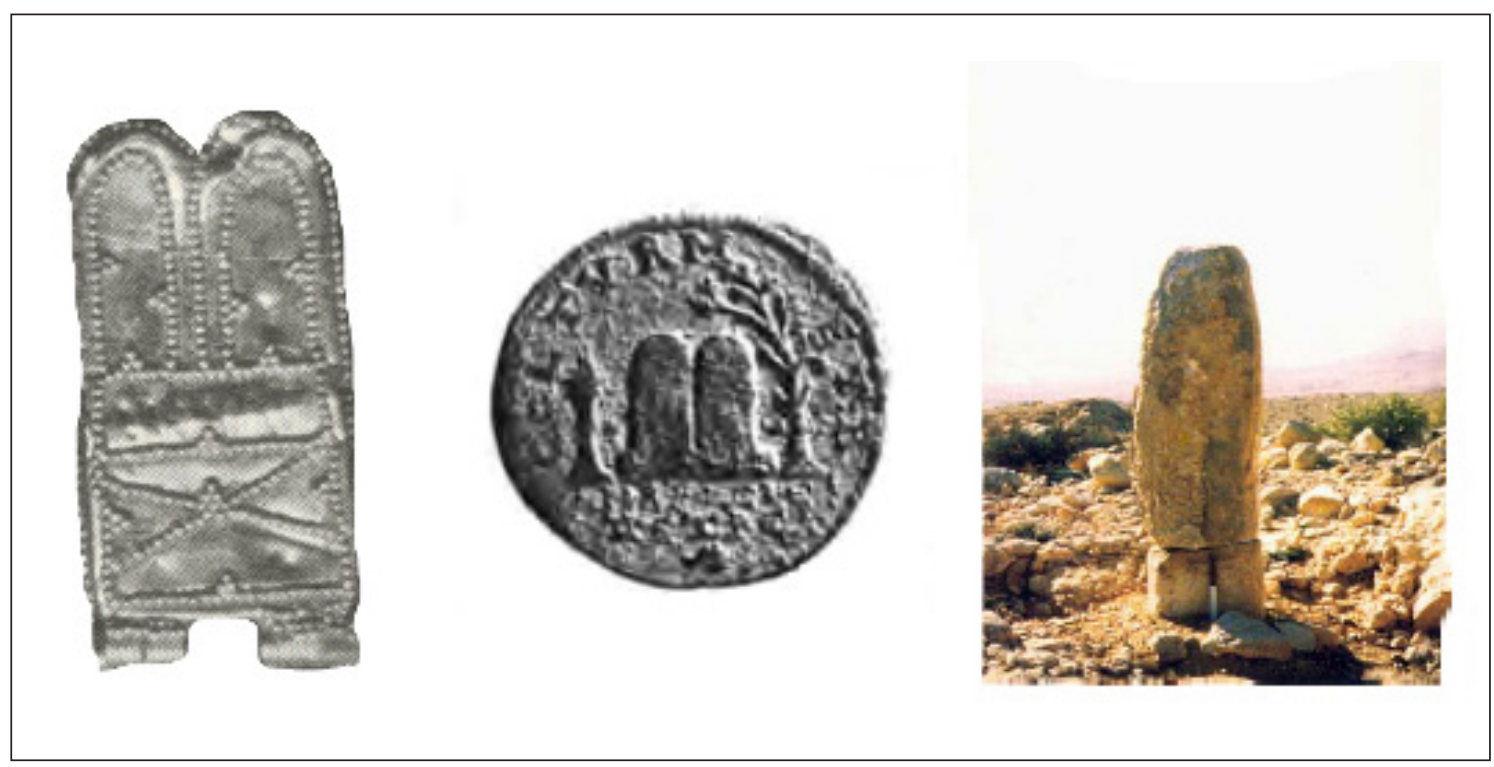

Figura 7. Izquierda) Masseboth. Centro) Rocas ambrosiales representadas en una moneda tiria de la época de Gordiano III (238-244 d.C.) (Bijovsky 2005: 834, fig. 6). Derecha) Massebah localizada en el corredor siropalestino (a partir de Avner 2001: fig. 1). 
tal y como apuntó Carriazo en su momento. Ambas piedras estarían colocadas sobre una peana marcada con un aspa de esquina a esquina (Fig. 7).

\subsection{Figura ANTROPOMORFA}

Si bien el conjunto de elementos acabados de analizar presenta una coherencia interna considerable, la última de las piezas plantea posibilidades interpretativas que aunque sugerentes hacen necesarias futuras revisiones. El cuarto motivo es una figura antropomorfa. En su mitad superior se observa una gran cara de rasgos marcados. Separando ambas mitades, dos brazos unen las manos en el centro. Y en el sector inferior el personaje muestra las piernas abiertas y flexionadas tapando su entrepierna con lo que parece ser un taparrabos. Por último, abajo del todo se ha representado un objeto incierto de forma redondeada.

Cuando se ha tratado de identificar a esta figura en la historiografía, por lo general se ha propuesto darle la identidad de Bes, personaje con connotaciones principalmente protectoras y propiciadoras de la fertilidad. Sin embargo los datos para proponer a este personaje son contradictorios. Mientras las características iconográficas de esta deidad menor no cuadran con el aspecto que muestra en la posible diadema de Ébora, otros datos procedentes del Mediterráneo Oriental podrían sugerir lo contrario.

Las cuestiones geográficas, cronológicas y transculturales de esta deidad hacen en un primer momento complejo su análisis. Desde fines del siglo XIX la tradición historiográfica ha venido escribiendo sobre la figura de Bes en el Antiguo Egipto en innumerables ocasiones y, desde hace varias décadas, a propósito de su papel en el mundo cananeo del II y i milenios a. C. Síntesis de indudable valor son las elaboradas por Tran Tam Tinh (1986: 98-108) a propósito de Bes en el Antiguo Egipto y por Hermary (1986: 108-112) para el caso de Bes en el mundo fenopúnico. Para este último caso su presencia en el mundo fenicio está bastante bien atestiguada, tanto en el corredor sirio-palestino como en las islas de Chipre (Yon 1986: 131 y ss.) y Creta (Tzavellas-Bonnet 1985), así como en la Península Ibérica (Velázquez 2007).

Se tiene constancia de las características iconográficas de su figura a partir del Imperio Nuevo (Gómez Lucas 2002: 89-90). A este respecto, Velázquez es quien mejor ha sabido sintetizar la cuestión de la unicidad o multiplicidad de identidades de las figuras enanas y grotescas halladas por los especialistas en el Antiguo Egipto, así como la multiplicidad de nombres para estas imágenes (Velázquez 2007: 12-19). Así, en el Imperio Nuevo, a su conocida imagen enana con las piernas arqueadas, las manos en los muslos y la piel de león cayendo por la espalda asomando la cola por entre las piernas, se sumarán su barba, su corona de plumas, su faldellín, e incluso a veces alas, del mismo modo que romperá su peculiar frontalidad en otras ocasiones.

Posteriormente, será a partir de época saíta cuando la iconografía de Bes vuelva a mostrar cambios en la barba, la cual terminará en pequeños bucles; la cadera, que se verá rodeada de un cordón; y la piel de león, que ahora tendrá sus cuartos delanteros sobre su pecho asomando Bes la cabeza por una abertura en la piel (Velázquez 2007: 29-30; Gómez Lucas 2002: 94). Por lo que respecta a la corona de plumas, que algunos relacionan con cultos de fertilidad, muestra dos tipologías opuestas. Por un lado, esta corona es representada con todo detalle, mientras que en otros casos el tocado es reconocible únicamente por la base que la sustenta, existiendo ambas iconografías en época ptolemaica y en el mundo romano (Arroyo 2007: 21). Sin embargo, aparte de las piernas flexionadas, ninguna de las características restantes se aprecian en la imagen del antropomorfo de la diadema de Ébora. Especialmente importante es que Bes no aparece sin corona de plumas en fechas anteriores al s. III a. C. (Gómez Peña y Rodríguez 2014: 161-162).

A partir de los paralelos indicados podría sugerirse no conectar la figura de la diadema de Ébora con Bes. Sin embargo, hay indicios para dudar a partir de un hallazgo procedente de Kuntillet 'Ajrud, yacimiento ubicado a $50 \mathrm{~km}$ al sur de Qadesh en la zona septentrional del Sinaí. El área de Kuntillet 'Ajrud cobra especial importancia por tratarse de un nodo de paso de diversas vías sin que en los alrededores existan ni poblaciones cercanas ni restos arqueológicos de ningún otro tipo. En este asentamiento se ha excavado un edificio que ha generado, desde sus primeras publicaciones a finales de los años setenta del pasado siglo, un debate interpretativo tanto por su planta como por sus materiales entre quienes se posicionan a favor de una función religiosa del edificio (Meshel 1978) y quienes consideran que se trata de un sitio en el que se habrían hospedado los comerciantes que por aquellas rutas habrían transitado, al estilo de los mālôn bíblicos (Hadley 2003: 112 y ss.).

Si ya de por sí las características de este sitio serían más que suficientes para llamar la atención de numerosos investigadores a uno y otro lado del Mediterráneo, el yacimiento cobra especial interés por varios pithoi fragmentados que aparecieron en su interior. De especial relevancia son los denominados como A y B por sus imágenes y las leyendas en ellos escritas. En el pithos A, infrapuesta parcialmente a una inscripción que recoge el teónimo de Yahweh de 


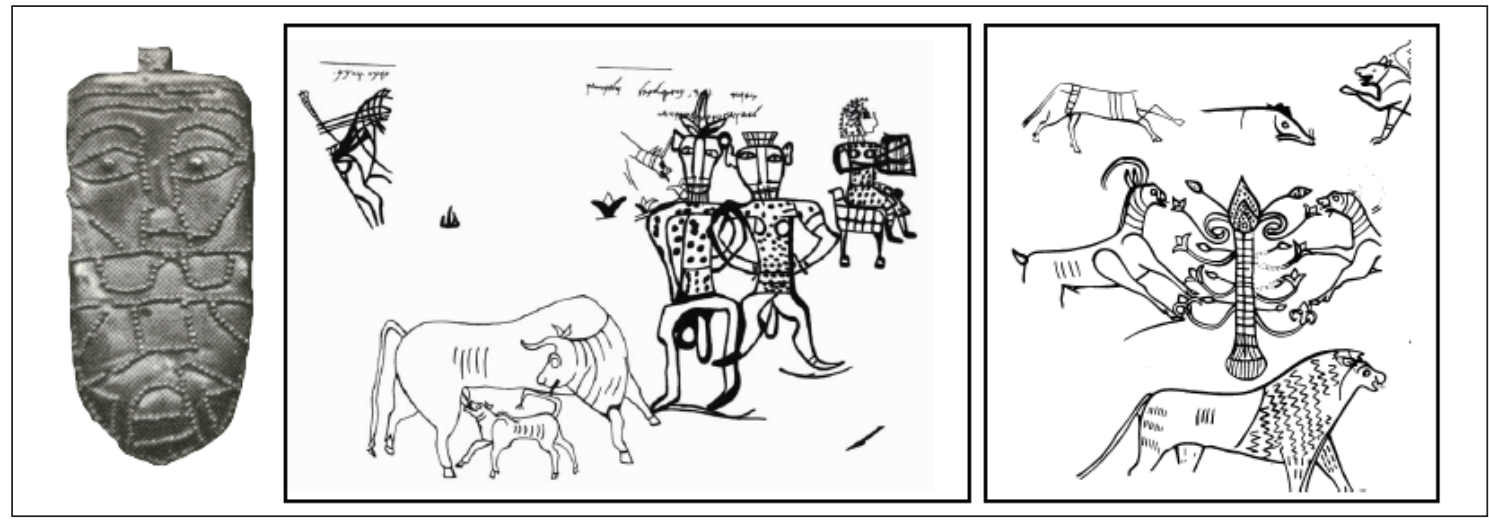

Figura 8. Izquierda) Figura antropomorfa. Centro) Bes y Beset representados en el pithos A de Kuntillet 'Ajrud. Derecha) Asherah dibujada en la cara opuesta del pithos A de Kuntillet 'Ajrud.

Samaria y su Asherah, aparecen dibujadas dos figuras de pie, acompañadas en segundo plano por una mujer sedente tocando la lira. Al igual que la función del sitio, la identificación de estos tres personajes ha sido de enorme controversia ${ }^{3}$. Para Meshel habría que identificar a la figura central con Bes, dejando sin referencia clara a su acompañante (Meshel 1978).

Otros autores van más allá y consideran que ambas imágenes representan a Bes (Stoltz 1980; Beck 1982; Dever 1984; Lemaire 1984; Keel y Uehlinger 1992). Hasta el momento no hay mejores alternativas para identificar a ambas figuras, en tanto que el aspecto grotesco, enanoide, su representación facial frontal, cola leonina cayendo entre sus piernas y corona de plumas le hacen inconfundible. Sin embargo, la superposición de estas figuras y el texto ha llevado a pensar a Hadley que se trata de elementos inconexos realizados por diferentes manos en diferentes momentos (Hadley 2003: 155), hipótesis que se sustenta para esta autora en la heterogeneidad y posición de otros varios elementos trazados sobre la superficie de la vasija, caso de diversos animales.

El motivo de traer a colación este ejemplo se debe a que en la parte trasera de la pieza se representó una posible asherah flanqueada por dos cabras que comen del árbol de la vida, y situada sobre un león, animal protector y sobre el que se posan en ocasiones las divinidades simbolizando su poder y majestuosidad como dominadoras de las fuerzas de la naturaleza. No es por supuesto descartable el carácter inconexo de algunos animales diseminados por su superficie, pero el tesoro de Ébora otorga conexión a la asherah, así como a la posible figura de Bes e incluso a la inscripción que aparece sobre el tocado de uno de

\footnotetext{
${ }^{3}$ Un repaso crítico sobre la historiografía de este asunto puede consultarse en Hadley 2003: 136 y ss.
}

estos, pues la relación entre Yahweh y su asherah no debería entenderse en clave hebrea, sino de un modo más aperturista dado el carácter de paso que tiene el sitio en el que se halló (Fig. 8).

La hipótesis de Bes permite explicar la figura antropomorfa del tesoro de Ébora a partir de las características que presenta el personaje y su posible relación, incierta por otro lado, con Asherah.

Además de esta propuesta, es posible plantear una segunda hipótesis de trabajo que necesita de tiempo y recorrido. La premisa de partida de esta nueva vía radica en considerar la representación antropomorfa de Ébora como la figura de un dios o de un héroe naciendo de la roca, representada en este caso por un betilo o una massebah. Apoyando esta idea como paralelo se encuentra la figura de Mitra, aquí utilizada como ejemplo de un mitema más amplio que enlaza con la tradición cananea.

A partir de los escasos testimonios escritos y de las imágenes halladas en los mitreos, se piensa que esta divinidad nació de una roca - la petra generatrix-bajo un árbol, cerca de un manantial sagrado. Se le suele representar con un gorro frigio, una antorcha y un cuchillo, elementos que portaba desde su nacimiento. Su relación con el toro al que da posteriormente muerte surgió cuando lo encontró pastando en las montañas. El joven dios trató de domeñarlo agarrándolo por los cuernos y montándolo sin éxito, si bien consiguió seguir aferrado a su cornamenta hasta agotarlo de cansancio, momento en el cual lo cogió por sus patas traseras y lo cargó sobre los hombros hasta su cueva. A su llegada, un cuervo enviado por el dios Sol le avisó de que debía matarlo en sacrificio, ante lo cual Mitra le clavó el cuchillo en el costado saliendo de su cuerpo trigo y de su sangre vino.

Para la interpretación de la figura antropomorfa de Ébora no acaban aquí los datos. La tauroctonía 
realizada por Mitra se acompaña la gran mayoría de las veces de una escena de banquete en la iconografía. Se trata de una cuestión secundaria a la propia muerte del animal, pero lo realmente importante es que el acto de la comida comunal ocurre sobre la propia piel del Toro Celeste recién defenestrado. En ella aparecen recostados tanto Mitra como el dios Sol. De ello se tiene constancia en varios relieves (Fig. 9).

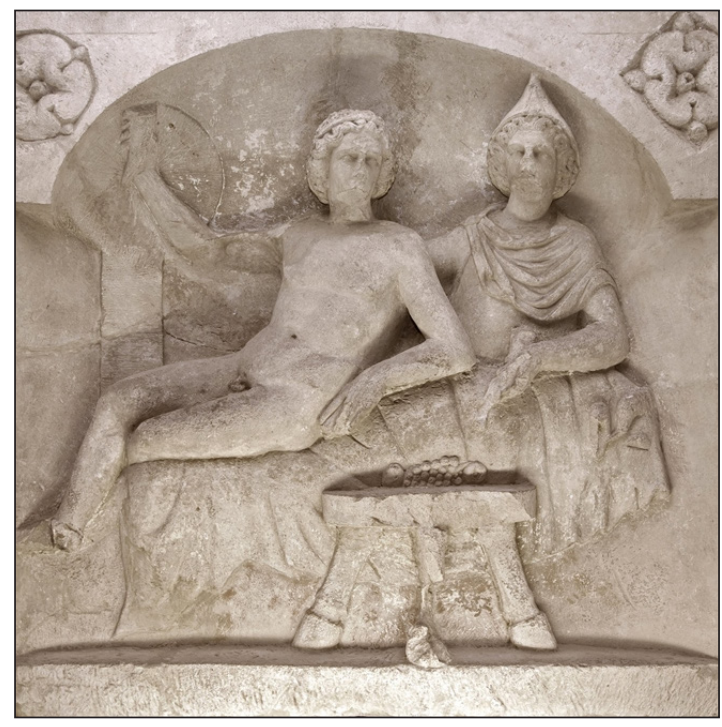

Figura 9. Bajorrelieve actualmente en el Museo de Lobdengau donde se aprecia a Mitra y el Sol reclinados sobre la piel del Toro Celeste (a partir de http://www.schule-bw.de/faecher-undschularten/gesellschaftswissenschaftliche-und-philosophischefaecher/landeskunde-landesgeschichte/module/bp_2016/spu ren_roemischer_herrschaft/staedte/lopodunum-vom_kastell_ zur_roemischen_stadt/1kurzbeschreibung.htm).

Sin entrar a valorar por falta de espacio las diferentes hipótesis sobre la simbología de la piel de toro en la tradición historiográfica (Gómez Peña 2012-2013), recientemente he propuesto una nueva interpretación para el simbolismo de la piel de toro extendida que encaja tanto con el ejemplo de Mitra como con los contextos sagrados en que la piel de toro aparece como superficie sagrada en la protohistoria del Mediterráneo (Gómez Peña 2017). Esta se basa parcialmente en la hipótesis del sacrificio fundacional elaborada por Almagro-Gorbea y sus colaboradores (AlmagroGorbea et alii 2011-2012), si bien la idea propuesta por estos autores necesitaba de mayor recorrido y concreción en algunos aspectos.

El hilo conductor de dicho mitema - en el que se inserta la figura de Mitra que ha servido de hilo introductorio para el presente asunto- es el sacrificio del Toro Celeste. En él, el animal es matado por un héroe ahijado del Sol, identificado normalmente con el monarca en una de sus múltiples hazañas heroicas. Tras dicha acción, la piel del bóvido es utilizada como asiento sobre el que se colocan presidiendo un banquete tanto la divinidad solar como el propio héroe. En torno a ella se realiza una comida que reúne a diversos personajes con motivo de un ritual de paso. Este puede consistir en la fundación de una fortaleza, un templo, un hogar familiar, dar entierro a un difunto o celebrar el Año Nuevo.

En función de qué narración se analice se verá que de los aspectos acabados de enumerar faltarán unos u otros, como toda tradición que presenta diversidad y mutaciones con el paso de los siglos. Por el contrario, cuando algunos de estos puntos no son mencionados en los textos, existen otros datos suplementarios que permiten plantear igualmente que se está ante este mitema. Quizás sea este mitema el que se encuentre detrás de varios ejemplos dentro de la tradición literaria fenicio-púnica. Sería el caso de la fundación del palacio de Baal según la mitología ugarítica, la fundación de Cartago por parte de Elisa y la de la Tebas griega por parte de Cadmo (Gómez Peña 2017).

Según esta segunda hipótesis, la figura antropomorfa representaría a Baal o a un monarca heroizado tras su muerte en tanto que antepasado heroico y fundacional de la realeza. Su vínculo con las otras tres piezas aquí analizadas vendría dado porque este personaje representaría al sacrificador del Toro Celeste, cuya piel habría sido usada como alfombra en banquetes fundacionales y rituales religiosos conmemorativos.

Por último, como tercera hipótesis cabe la posibilidad de unir ambas propuestas de trabajo y aceptar que el personaje representado sería Bes o una divinidad "besizada" entre cuyas piernas se habría representado un betilo. Un posible paralelo para esta poco usual mezcla podría ser el hallado en el templo de Astarté del yacimiento chipriota de Kition. En su interior se encontró un pilar adquirido por el Museo del Louvre en 1902 de 0,42 m de altura. Sobre su superficie se documentó una inscripción fenicia que se ha datado, por su estilo, en el s. viI a. C. y que ha sido traducida como: "Esto fue hecho por Eshmounhillç, el escultor, para su Señor, para Reshef Shed"4. El segundo de los objetos es una cabeza localizada junto al pilar que por sus rasgos ha sido considerada como propia de Bes (Fig. 10). La proximidad de ambas piezas, y el hecho de que encaje una sobre la otra llevó a Hermary a plantear la posibilidad de que la cabeza de Bes hubiera descansado en origen sobre el poste de piedra que habría hecho las veces de betilo o

${ }^{4}$ Traducción propia de la realizada al francés por Hermary (1984: 239). 


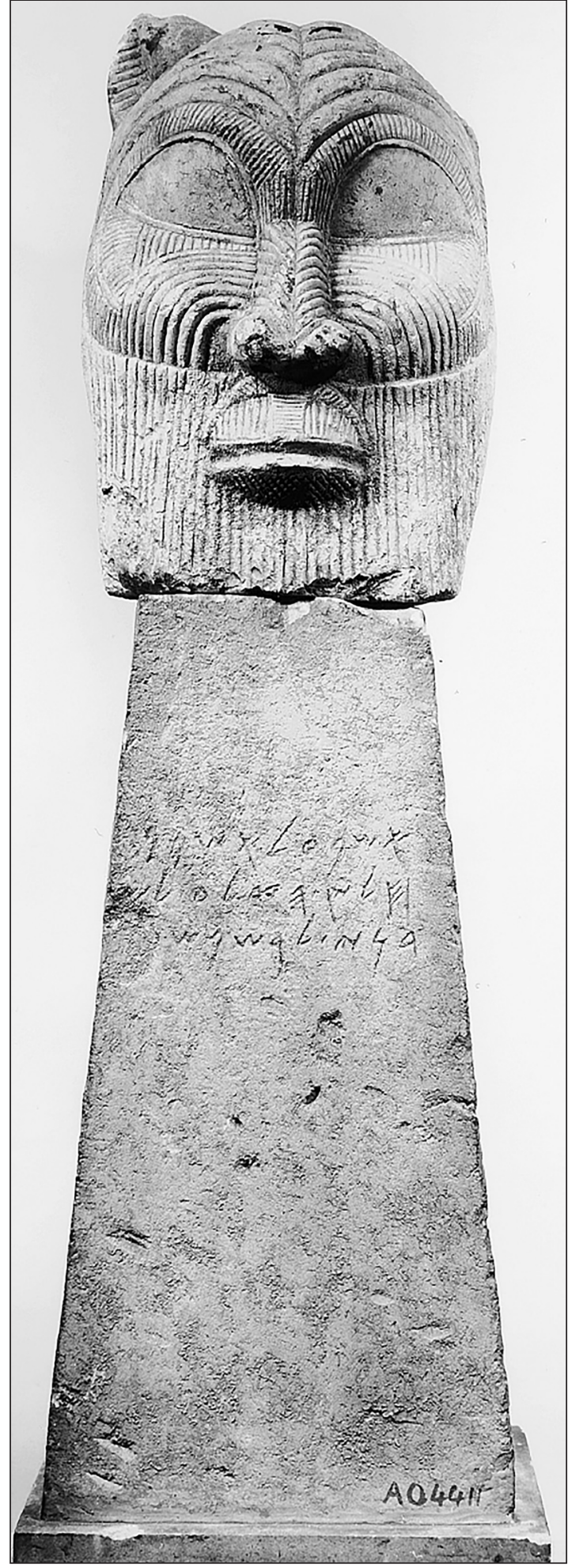

Figura 10. Escultura con cabeza "de estilo Bes" dedicada a Reshef-Shed (Counts y Toumazou 2006: 599). de massebah (Hermary 1984; Shaw 1989: 175-176; Schmidt 2016: 207 y ss.). Siguiendo la interpretación de autores como Schmidt, esta escultura podría ser el reflejo de una hibridación del culto a una divinidad claramente semítica como Reshef con los rasgos propios de Bes (Schmidt 2016: 208).

Esta última propuesta tiene varios puntos a su favor. Por una parte, la datación del pilar en torno al siglo VII a. C. hace coetánea a la pieza chipriota con la cronología aproximada de la posible diadema de Ébora. Por otro lado, la posibilidad de que la cabeza de Bes hubiese ido colocada sobre el pilar permite dar una lectura más completa de la figura antropomorfa del tesoro hallado en Sanlúcar de Barrameda tal y como se ha propuesto en la tercera de las hipótesis aquí comentadas.

\section{REFLEJOS DE ESTA SIMBOLOGÍA EN LA ARQUEOLOGÍA PROTOHISTÓRICA DE LA PENÍNSULA IBÉRICA}

La tríada altar-asherah-massebah se encuentra en ocasiones en varios santuarios de tradición feniciopúnica a lo largo de la Península Ibérica. No hay tanta suerte sin embargo con la identidad que pudiera hallarse detrás de su figura antropomorfa. Ni Bes ni la posible representación de un héroe o una divinidad naciendo de la roca han sido localizados en los mismos contextos, toda vez que las representaciones humanas en estos lugares son escasas dado el carácter anicónico de la religiosidad cananea. No obstante, no se trata de la única referencia a "imágenes del tipo Bes" dentro de dicha tradición. Existen más ejemplos procedentes de Chipre (Counts y Toumazou 2006), Cerdeña (Pesce 1965; Agus 1983) y la Península Ibérica (Velázquez 2007; Gómez Peña y Rodríguez 2014), entre otros lugares.

A propósito de la tríada ya indicada, los ejemplos que se recogen sucintamente a continuación se incluyen en este apartado por tener como mínimo dos de los cuatro elementos que anteriormente se han analizado. En todos los casos, como mínimo se han detectado altares con forma de piel de toro y restos de posibles árboles sagrados. En los dos últimos contextos, ambos fechables durante el Hierro II, hay que sumar la presencia de masseboth que completan la tríada de elementos religiosos de tradición cananea que aparecen citados repetidamente a lo largo de la Biblia.

Sigue quedando por lo tanto pendiente una identificación más clara para la figura antropomorfa del tesoro de Ébora que minimice las dudas ofrecidas tanto por anteriores hipótesis como por las que aquí se proponen. 


\subsection{Hierro I}

\subsubsection{El Carambolo}

Cuando se descubrió el tesoro de El Carambolo a fines de los años cincuenta, las excavaciones que dirigió Carriazo para conocer el contexto del que procedía el hallazgo le llevaron a pensar en la identificación de un poblado tartésico que comenzaba en el Bronce Final, momento en que se dató el lote de piezas áureas (Carriazo 1970: 58). Poco después, Blanco Freijeiro interpretó el yacimiento de El Carambolo como un lugar de culto tartésico influenciado por los santuarios de época geométrica del área egea dado lo básico de las construcciones y lo singular de los ajuares (Blanco Freijeiro 1979: 95-96).

Esta idea se mantuvo en líneas generales hasta la reinterpretación realizada por Belén y Escacena (1997). Ambos investigadores revisaron en una publicación algunos de los materiales encontrados en dichas excavaciones por Carriazo y acabaron concluyendo que el yacimiento de El Carambolo no había sido un asentamiento tartésico originado en el Bronce Final, sino un templo de tradición oriental dedicado a Astarté. La repisa enlosada de sillares fue reconsiderada como banco corrido de tradición marcadamente oriental. Las "piedras raras", en expresión de Carriazo, fueron reinterpretadas como betilos anicónicos y el supuesto fondo de cabaña como un pozo o fosa ritual. Además, sus principales edificaciones, enclavadas en el denominado Carambolo Bajo, habrían sido las dependencias propias de estos edificios empóricos dependientes de la fundación de Ispal (Belén 2001: 7).

Pocos años después, entre 2001 y 2005, se realizaron nuevas excavaciones en El Carambolo en las que llegó a excavarse la casi totalidad del cerro. Los resultados depararon el hallazgo de un complejo sagrado de tradición oriental con cinco fases constructivas en el que se hallaron dos altares con forma de piel de toro (Fernández y Rodríguez 2007). Se trata de las aras con este perfil más antiguas encontradas hasta el momento en la Península Ibérica, cada una de las cuales pertenece a las fases IV y III respectivamente (Fig. 11).

El altar que pertenece a la fase IV, documentado en el centro de la estancia A-40, fue realizado a partir de un rebaje en el suelo de 3,05 $\mathrm{m}$ de largo por 1,42 $\mathrm{m}$ de ancho. El equipo que realizó las intervenciones en El Carambolo apreció cuatro reformas del ara y un gran círculo rubefactado producto de la combustión de las ofrendas sobre la misma (Fernández y Rodríguez 2007: 120). Formalmente, el hogar muestra una diferencia de color entre la zona exterior y la interior, la primera más clara que la segunda. La datación propuesta para la más antigua de las dos fases según cronología absoluta es entre 830/810 a. C. - fecha post quem de la fase $\mathrm{V}-\mathrm{y}$ el 791 a. C. - fecha ante quem de la fase III- como uso mínimo de la fase IV (Fernández y Rodríguez 2007: 125).

Por lo que respecta al altar de la fase III, también excavado en la estancia A-40 y superpuesto al anterior, fue nuevamente elaborado en el pavimento. Los

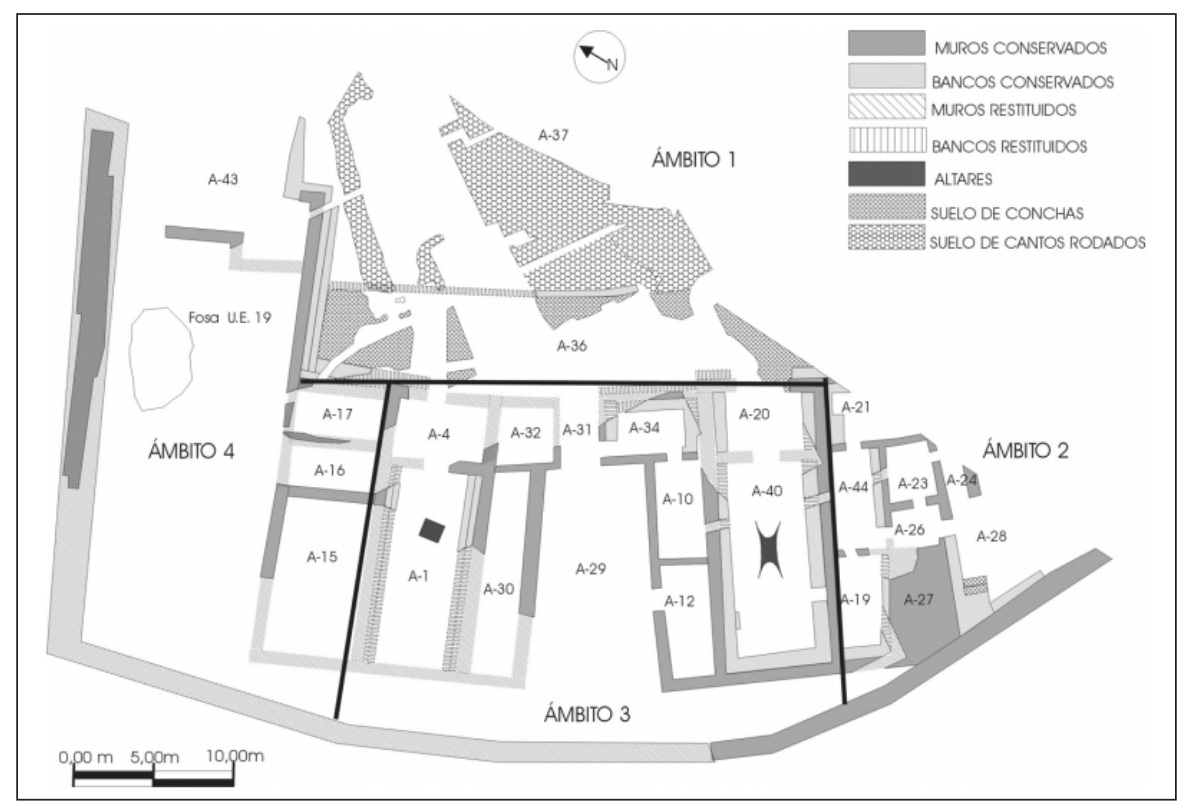

Figura 11. Planta del santuario de El Carambolo III (Fernández y Rodríguez 2005: 125). 
arqueólogos que lo hallaron indican que fue realizado recubriendo con una capa arcillosa de dos a cuatro cm de grosor el altar previo. En dicha capa se modeló en negativo la forma de la piel extendida con unas dimensiones de $4 \mathrm{~m}$ de longitud por 1,90 $\mathrm{m}$ de ancho que ha llegado hasta nuestros días con marcas de combustión en su superficie (Fernández y Rodríguez 2007: 136-137). Para esta fase, la fecha propuesta a partir de datación absoluta por C14 ofrece un arco cronológico calibrado de 791-506 a. C.

Igualmente, muy cerca del altar de esta fase se documentó en su extremo noreste una pequeña oquedad circular formada por un pequeño adobe rehundido con una capa de mortero a base de tierra margosa (Fernández y Rodríguez 2007: 120), que acaso pudo haber servido para colocar en ella una asherah. Altar y asherah se ubicaron en la estancia A-40, en la cual se encontró a lo largo de todo su perímetro interior una grada enlucida de rojo (Fernández y Rodríguez 2007: 118-119) que podría haber hecho las veces de banco corrido.

\subsubsection{Caura}

El asentamiento tartésico de Caura se localizaba donde hoy se encuentra la población de Coria del Río. El parecido entre ambos topónimos y las numerosas acuñaciones con este nombre procedentes de sus inmediaciones anclan fuertemente este término con el actual municipio sevillano. Para su significado se ha propuesto conectar el nombre de Caura con una antigua raíz de origen indoeuropeo cau- que significa 'grande', 'hinchado', 'prominente' (Padilla 1993) con el que quizás se hiciera referencia al actual cerro de San Juan, el punto más alto de la localidad.

Muy cerca geográficamente de El Carambolo, su ubicación sobre un promontorio justo en la antigua paleodesembocadura del Guadalquivir (Arteaga et alii 1995) supuso un punto estratégico para el comercio colonial. Ya antes de efectuarse excavaciones en él, Belén había planteado la hipótesis de que en el lugar podría haberse ubicado un edificio con evidencias de culto identificable con el Mons Cassius de la Ora Marítima de Avieno (Belén 1993). La presencia de este topónimo en la paleodesembocadura del Guadalquivir fue anotada en la obra de Rufo Festo Avieno, quien a pesar de ser un escritor latino del siglo IV d. C. basó su periplografía en fuentes más antiguas, como él mismo reconoció. Independientemente de si el relato debe de ser considerado un periplo más marinero que poético o viceversa, la concordancia entre el uso de fuentes como la de Escílax de Carianda — segunda mitad del siglo vi a. C.—, Euctemón de Atenas — hacia 435 a.
C.—, Damasto de Sige — hacia 420 a. C.—, Fileas de Atenas — siglo v a. C.— y el empleo de la expresión Cassius inde mons tumet (AVIEN. ora, v. 259) hacen pensar en que el Monte Casio hace referencia a la identificación de un antiguo enclave bajo su forma helenizada. Afortunadamente está bien constatada la equivalencia del Zeus Casio griego con la antigua divinidad cananea de tradición marinera Baal Saphon, denominada así por la montaña ugarítica Sapanu en la que vivía (Bonnet 1987; Tito 2012: 83-85)5.

La hipótesis de Belén (1993) se reforzó poco tiempo después al hallarse en dicho cerro parte de un edificio singular con cinco fases constructivas sucesivas en el que aparecieron nuevamente dos altares taurodérmicos superpuestos. Los restos exhumados hasta la fecha corresponden a parte de un edificio cuya habitación presidida por el altar linda en su zona occidental con una posible calle exterior. Esbozar una posible planta para la totalidad del inmueble resulta tentador. Escasos años después de la excavación en el cerro de San Juan, Escacena e Izquierdo (2001: 131) propusieron restaurar la totalidad de la planta basándose en la de Cancho Roano, cuestión que deja una duda a propósito de la ubicación del altar, pues no corresponde con la misma que presenta el edificio extremeño y por lo tanto la distribución funcional de las estancias podría haber sido diferente. A pesar de ello, la hipótesis barajada para la estructuración interna de un edificio hallado en Lorca presenta este mismo problema (Gallardo et alii 2008; Cárceles et alii 2011).

Este templo tartésico de dilatada cronología se inserta en un espacio donde ya existía previamente poblamiento local limitado a la franja sureste del cerro, el de mayor proximidad al Guadalquivir. Sólo con posterioridad, a partir del siglo viII a. C. se continuó la expansión del asentamiento hacia la zona septentrional y la occidental. Así, tanto el santuario como el barrio colonial habrían estado situados en dicho cerro de San Juan, acompañado de una pequeña necrópolis en el cercano cerro de Cantalobos (Belén 1993; Escacena 2001: 81).

En cuanto al santuario, de las cinco fases constructivas que posee el edificio, la sala mejor conocida es la interpretada como capilla del Santuario III (Fig. 12). En el centro de la estancia apareció el altar taurodérmico fabricado a partir de una mesa rectangular de barro de color castaño que fue enlucida con una

\footnotetext{
${ }^{5}$ El propio apelativo hurrita Hazi del que derivó el término helenizado Casio hacía alusión a la montaña sagrada identificable con Djebel el-Aqra' de Ras Shamra (la antigua Ugarit), donde se creía que residía la divinidad. La equiparación entre Baal Saphon y Hadad se hace patente en el uso para el segundo del epíteto Baal de Hazi (KTU 1.101: 1-4).
} 


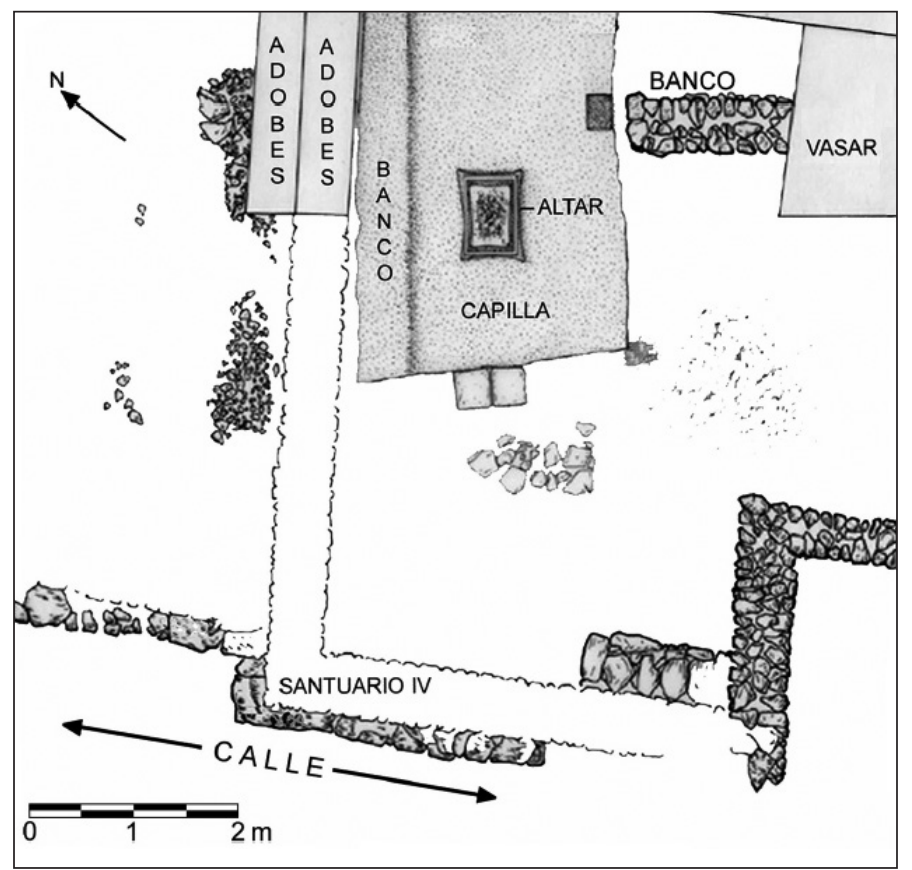

Figura 12. Superficie excavada del Santuario III de Caura (Escacena 2007: 645).

capa amarillenta también de barro y posteriormente pintada con una fina película roja. Una vez realizado esto, todo el bloque se volvió a rodear con una capa blancuzca-amarillenta hasta modelarse su forma de piel de toro con una protuberancia en su lado superior durante la fase A, la cual parece que no tuvo durante la posterior fase B. Realizada su forma, el altar volvió a ser pintado de ocre rojo (Escacena 2001: 87; Escacena e Izquierdo 2001: 133). Sobre él se documentaron restos cenicientos que gracias a recientes analíticas han confirmado la existencia de restos de sebo propio de ovejas y cabras que habrían sido quemados sobre él (Escacena y Coto 2010: 163).

Por otro lado, junto al extremo superior derecho del ara apareció en la fase A un círculo negro de unos $20 \mathrm{~cm}$ de diámetro conteniendo carboncillos, huella al parecer de un cilindro de madera hincado en posición vertical que tampoco se ha documentado en la fase B. Cuando Escacena e Izquierdo publicaron estos datos hipotetizaron con la posibilidad de estar ante una posible asherah (Escacena e Izquierdo 2001: 134). Igualmente, en el edificio se encontraron otros elementos de tradición y simbología oriental, caso de escarabeos, lucernas de barniz rojo y huevos de avestruz que ahondan en el carácter semita del santuario, así como suelos pintados de ocre que suelen ir asociados a espacios sagrados de tradición oriental en el ámbito tartésico (Escacena 2001: 90-92; Conde et alii 2005).

\subsection{HiERro II}

\subsubsection{Castellet de Banyoles}

En el área del Bajo Ebro se desarrolló un sistema de asentamientos fortificados entre los siglos V-III a. C. La zona íbera del eje del Ebro quedó articulada por tres oppida que actuaron como centro de sus respectivos territorios: Dertosa en la zona oriental, Osicerda en El Palao de Alcañiz en el área occidental y Castellet de Banyoles en Tivissa. Con la desaparición de este último en la transición entre el Ibérico Pleno y el Ibérico Tardío, el territorio dependiente de él quedó repartido entre los dos primeros, dominando los últimos la Ilercavonia íbera (Burillo 2012: 107).

El yacimiento íbero de Castellet de Banyoles, de 4,5 ha, se encuentra en una plataforma formada por una antigua terraza fluvial junto al río Ebro, a unos $7 \mathrm{~km}$ de Tivissa (Tarragona). Desde la plataforma sobre la que se eleva, tuvo que ejercer un control casi total desde la hoya de Mora y la vía que conecta dicha cubeta con la costa a través de Tivissa, así como el camino que va hasta la desembocadura del Ebro. Este asentamiento destacó como centro que capitalizó la zona como mínimo desde el siglo IV a. C. Su importancia se refleja tanto en el tamaño del yacimiento como en la densidad de sus edificaciones, la complejidad que muestra la arquitectura de sus edificios y la enorme cantidad de objetos de 


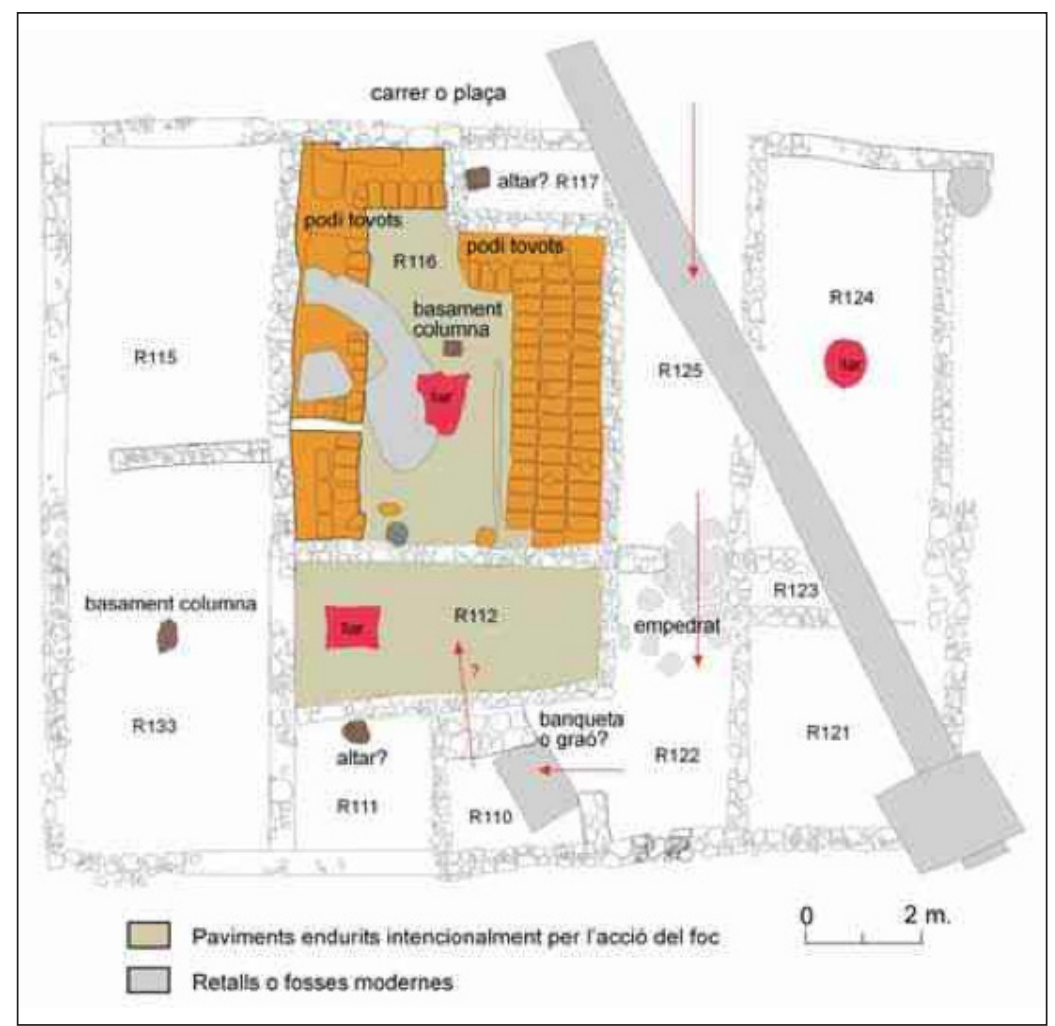

Figura 13. Planta del santuario de Castellet de Banyoles (Álvarez et alii 2008).

metal hallados en el interior del recinto para lo que es habitual en el Bajo Ebro. Estos datos han llevado a plantear que Castellet de Banyoles podría haber ejercido el control de la explotación y distribución de metales en la desembocadura del Ebro (Rafel et alii 2010: 184-185).

El poblado cobró fama en la historiografía íbera desde la primera mitad del siglo xx por el hallazgo de varias monedas y objetos metálicos de prestigio, así como por la excavación de un acceso al poblado en su zona oriental formado por dos torres pentagonales y un área habitacional al sudoeste de dichas torres durante los años cuarenta. Sin embargo, hubo que esperar hasta 1998 para el hallazgo en la parte noroccidental del yacimiento de parte de su muralla, varias calles y casas, así como un edificio de posible uso cultual (Sanmartí et alii 2012: 45-47).

Este último, denominado Edificio 10 (Fig. 13), presenta una extensión en torno a los $140 \mathrm{~m}^{2}$ y una disposición interna con particularidades con respecto al resto de recintos del poblado. Se trata de un ámbito de planta casi cuadrada - R116 - con una pequeña cámara —R117 - y una antesala alargada —R112 Tanto el suelo de R112 como el de R116 estuvieron realizados a base de tierra rubefactada por la acción de un fuego intencionado. Este presentaba además varias hiladas de adobes a modo de plataforma pegada a las paredes que podrían corresponder a las bases de unos bancos corridos en tres de las cuatro caras de la habitación. En el centro de la estancia, a una cota inferior, se encuentran un hogar de tendencia rectangular — quizás con forma de piel de toro-y una base de una posible columna labrada de piedra arenisca que no es propia de la zona. A su vez, otras dos superficies susceptibles de ser catalogadas como altares se hallaron en la sala anterior R112, esta vez con forma taurodérmica mucho más nítida y en la pequeña estancia interior R117 una piedra puesta sobre otras dos (Álvarez et alii 2008: 94; Asensio et alii 2012: 186).

Todos estos datos permiten proponer dos posibilidades para este yacimiento. O bien el complejo sagrado de Castellet de Banyoles constituyó un único edificio con su entrada a través de la estancia R110, o bien se trata de dos edificios diferentes que presentan la característica planta oriental con una estancia principal y una sala anexa de menores dimensiones. El primero con su entrada por R110 y el segundo sin entrada localizada. Ambos espacios se dividirían respectivamente en una sala principal con un altar 


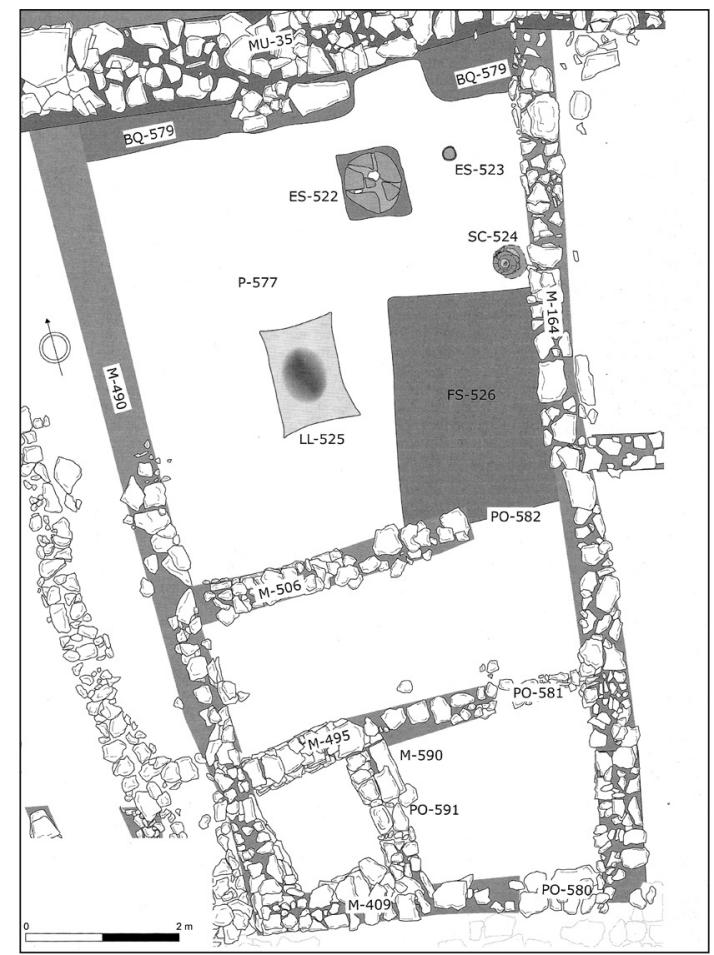

Figura 14. Planta del edificio 11/3 de Els Vilars (Grup d'Investigació Prehistòrica 2005: 659).

taurodérmico cada una - R112 y R116- y dos capillas secundarias que habrían albergado la base de su respectiva massebah - R111 para el primer caso y R117 para el segundo-. Igualmente, la habitación R116 presenta una base interpretada como columna que podría haber sido en realidad la parte inferior de la representación de una asherah. De ser cierta esta interpretación podría tratarse de dos santuarios dedicados a Baal y Astarté.

\subsubsection{El edificio $11 / 3$ de Els Vilars}

El asentamiento de Els Vilars (Arbeca, Lleida) se sitúa en la comarca de Les Garrigues, en el margen izquierdo del río Segre. El yacimiento presenta una planta ovalada fortificada trazada a cordel con una superficie aproximada de $2200 \mathrm{~m}^{2}$, presentando escasas modificaciones desde su fundación en el siglo viII a. C. hasta su abandono a finales de siglo IV a. C. Los elementos defensivos de Els Vilars los constituyen una muralla que cuenta con doce torres, un mar de piedras hincadas al exterior y un foso en talud (Grup d'Investigació Prehistórica 2005: 652). En su interior, la disposición del poblado se articula de manera radial en torno a una plaza central en la que destaca un pozo-cisterna desde la mitad del siglo v a. C. (Grup d'Investigació Prehistórica 2005: 652).

Estratigráficamente, el asentamiento de Els Vilars muestra tres horizontes culturales y cinco fases a partir de las modificaciones urbanísticas y arquitectónicas que se han observado tras las sucesivas campañas de excavación (Grup d'Investigació Prehistórica 2005: 654). El motivo por el que se incluye en este estudio a Els Vilars no es otro que el hallazgo de dos hogares taurodérmicos en sendas estancias que aportan datos de gran interés. En concreto, los altares aparecieron en los sectores 6/13 y 11/3, adscritos a la Fase Vilars IIb: 500/475-450 a. C. y por lo tanto coetáneos en el tiempo (Grup d'Investigació Prehistórica 2005: 652).

Por las características observadas en su interior hay que analizar aquí el correspondiente al sector $11 / 3$. Este edificio tiene aproximadamente $55 \mathrm{~m}^{2} \mathrm{y}$ presenta una planta trapezoidal (Fig. 14). La compartimentación interna se encuentra dividida en tres estancias comunicadas a través de puertas rinconeras al este de los muros. La primera de ellas ha sido interpretada como un vestíbulo parcialmente enlosado - sector $3 \mathrm{~A}$ - que se encuentra conectado tanto con la calle como con una pequeña habitación — sector 3D-. El siguiente espacio es una sala intermedia - sector 3C - que conecta el vestíbulo con la sala 
principal—sector $3 \mathrm{~B}-$. En dicha sala principal se han documentado tres suelos diferentes pintados con arcilla roja, recrecido tras recrecido, en cuyo centro se han hallado otros tantos hogares superpuestos con orientación norte-sur (Grup d'Investigació Prehistórica 2005: 657-658). Este enlucido sucesivo afectó también a las paredes y estructuras donde se ven varios revestimientos milimétricos (Grup d'Investigació Prehistórica 2005: 661). Este repintado cuenta con paralelos en El Carambolo y en Caura.

El primero de los altares no tiene forma taurodérmica, sino cuadrangular (LL-528). Sin embargo presenta en el exterior un ribeteado amarillento tal y como muestran otros ejemplares del área tartésica. También tiene paralelos en otros yacimientos del suroeste ibérico la rubefacción de sus superficies por el uso del fuego sobre ellos. Justo al sur del altar se ha encontrado una pequeña oquedad semicircular de $25 \mathrm{~cm}$ de anchura y $6 \mathrm{~cm}$ de profundidad, rellena de cenizas, equiparable al receptáculo que muestra el ejemplar de Caura posiblemente para recoger la sangre de las víctimas. En cuanto a la segunda de las aras (LL-525), construida sobre la anterior, también pintada de rojo y manteniendo el mismo eje norte-sur, ya sí se observa su característica forma de piel con las esquinas apuntadas con signos de rubefacción en su superficie. Lo mismo puede decirse para la última de las fases (LL-520), presentando como novedad un reborde de otra tonalidad (Grup d'Investigació Prehistórica 2005: 658-660).

Además del altar, se ha documentado una base para un soporte circular de $80 \mathrm{~cm}$ de diámetro que conserva apenas $10 \mathrm{~cm}$ de su altura original (ES-522). Este podio fue elaborado con fragmentos de adobes troceados y pequeñas piedras, con una capa de barro que la regulariza y le da un acabado (Grup d'Investigació Prehistórica 2005: 660). Siguiendo la interpretación para otros contextos en el que he propuesto la existencia de la tríada altar-asherah-massebah, en este caso podríamos estar ante el último de los tres. Este tendría —al igual que en otros ejemplos- la base que aísla a la massebah del suelo, de la cual sólo se habría conservado parte de su zona inferior. Por otro lado, la asherah se habría situado a $60 \mathrm{~cm}$ de la massebah, donde se ha encontrado un cilindro de arcilla de $20 \mathrm{~cm}$ de diámetro hincado en el suelo (ES523) (Grup d'Investigació Prehistórica 2005: 664). De él tan sólo se han podido documentar $14 \mathrm{~cm}$ por encima del nivel del pavimento (Grup d'Investigació Prehistórica 2005: 660).

Además de esta tríada de elementos de tradición oriental, en la misma sala se halló la base umbilicada de un posible pithos cerámico encajado en una fosa de $35 \mathrm{~cm}$ de diámetro (SC-524) que estuvo en uso de manera coetánea a las dos primeras aras. En su interior se ha encontrado una cadenita de bronce que para sus excavadores pudo haber servido para sujetar la pieza con la que se habrían extraído los líquidos de su interior (Grup d'Investigació Prehistórica 2005: 661).

$\mathrm{Al}$ igual que se ha sugerido la posibilidad de estar ante dos templos diferentes dentro del Castellet de Banyoles, resulta sugerente plantear una división del espacio similar para el caso de Els Vilars. Sin embargo, tres son los problemas con que se encuentra esta posibilidad. En primer lugar, la estancia principal albergaría en esta ocasión no sólo el altar y la asherah, sino también otros elementos sagrados como la massebah. En segundo lugar, la habitación terminaría en el muro M-495, sin poder precisarse la utilidad del zócalo M-506. Por otro lado, el ámbito 6/13 antes descrito carece de estancia menor anexa. Para proponer que los dos edificios de Els Vilars habrían sido santuarios independientes dedicados a Astarté y Baal con una sala principal y una sala menor contigua habría que salvar estos tres escollos arqueológicos.

\section{BREVES CONCLUSIONES}

A tenor de los datos aportados en este estudio se propone reinterpretar la simbología de las piezas de la diadema de Ébora a partir de la tríada altar-asherahmassebah, a la que habría que sumar la representación de Bes — con paralelos en Kuntillet 'Ajrud_-, de un héroe divinizado naciendo de la piedra — como se ha observado en los casos de Mitra inserto en el mitema del ancestro fundacional que da muerte al Toro Celeste - o de una divinidad fenicia hibridada con Bes — cuyo paralelo más claro es el procedente del santuario de Astarté de Kition-.

Este conjunto de elementos encuentra paralelos en primer lugar en la literatura bíblica. Los pasajes en los que aparecen citados estos objetos resultan especialmente interesantes dado que se pide a la población israelí que derrumbe los altares, corte las asherim y derribe las masseboth, pues eran símbolos religiosos de las comunidades fenicias que dominaban el comercio en la región. Junto a estos ejemplos orientales existen muestras de estos objetos formando parejas o tríadas dentro de la protohistoria de la Península Ibérica. Es lo que se ha pretendido demostrar a partir de los contextos de El Carambolo y Caura en fechas del Hierro I, y en los de Castellet de Banyoles y Els Vilars datables en el Hierro II. En todos los casos se puede afirmar que se está ante templos en los que se practicaron cultos de tradición oriental, las mismas creencias que parecen estar detrás de la simbología del tesoro de Ébora. 


\section{BIBLIOGRAFÍA}

Agus, P. 1983: "Il Bes di Bithia", Rivista di Studi Fenici XI (1), 41-47.

Almagro-Gorbea, M. 1977: El Bronce Final y el Período Orientalizante en Extremadura, Madrid.

Almagro-Gorbea, M. y Lorrio, A. J. 2011: Teutates. El héroe fundador y el culto heroico al antepasado en Hispania y en la Keltiké, Madrid.

Almagro-Gorbea, M., Lorrio, A. J., Mederos, A. y Torres, M. 2011-2012: "El mito de Telepinu y el altar primordial en forma de piel de toro", Cuadernos de Prehistoria y Arqueología 37-38, 241-262. https://doi.org/10.15366/cupauam2012.38.012

Almagro-Gorbea, M. y Torres, M. 2011: La escultura fenicia en Hispania, Madrid.

Álvarez, R., Asensio, D., Jornet, R., Miró, M. T. y Sanmartí, J. 2008: "Residències aristocràtiques al món ibèric septetrional. El cas del Castellet de Banyoles (Tivissa, Ribera d'Ebre, Tarragona)", J. Blánquez, S. González y L. Roldán (eds.), La Cámara de Toya y la arquitectura monumental ibérica, Madrid, 87-102.

Amores, F. y Escacena, J. L. 2003: “De toros y de tesoros: simbología y función de las joyas de El Carambolo", A. García-Baquero y P. Romero (eds.), Fiestas de toros y sociedad, Sevilla, 41-68.

Arroyo, M. A. 2007: "Evolución iconográfica y significado del dios Bes en los templos ptolemaicos", Espacio, tiempo y forma. Serie II, Historia Antigua 19-20, 13-40.

Arteaga, O., Schulz, H. D. y Roos, A. M. 1995: “El problema del «Lacus Ligustinus»: investigaciones geoarqueológicas en torno a las marismas del Bajo Guadalquivir", Tartessos: 25 años después, 19681993, Jerez de la Frontera, Jerez de la Frontera, 99-135.

Asensio, D., Sanmartí, J., Jornet, R. y Miró, M. 2012: "L'urbanisme I l'arquitectura domèstica de la ciutat ibèrica del Castellet de Banyoles (Tivissa, Ribera d'Ebre)", J. Blánquez, S. González y L. Roldán (eds.), La Cámara de Toya y la arquitectura monumental ibérica, Madrid, 173-193.

Avner, U. 2001: "Sacred Stones in the Desert", Biblical Archaeology Review 27, 30-41.

Beck, P. 1982: "The Drawings from Horvat Teiman (Kuntillet 'Ajrud)", Tel Aviv 9, 3-68. https://doi. org/10.1179/033443582788440827

Belén, M. 1993: "Mil años de historia de Coria: la ciudad prerromana", Azotea 11-12, 35-64.

Belén, M. 2001: "Arquitectura religiosa orientalizante en el Bajo Guadalquivir", D. Ruiz y S. Celestino (eds.), Arquitectura oriental y orientalizante en la Península Ibérica, Madrid, 1-16.
Belén, M. y Escacena, J. L. 1997: “Testimonios religiosos de la presencia fenicia en Andalucía occidental", Spal 6, 103-131. https://doi.org/10.12795/ spal.1997.i6.07

Bendala, M. 1977: "Notas sobre las estelas decoradas del suroeste y los orígenes de Tartessos", Habis 8, 177-206.

Bijovsky, G. 2005: "The Ambrosial Rocks and the sacred precinct of Melqart in Tyre", C. Alfaro, C. Marcos y P. Otero (coords.), XIII Congreso Internacional de Numismática, vol. I, Madrid, 829-834.

Binger, T. 1997: Asherah. Goddesses in Ugarit, Israel and the Old Testament, Sheffield.

Blanco, J. L. y Celestino, S. 1998: "La joyería orientalizante peninsular. Diversidad y particularidades a la luz de los últimos hallazgos", Complutum 9, 61-83.

Blanco de Torrecillas, C. 1959: "El tesoro del cortijo de «Evora»", Archivo Español de Arqueología XXXII, 50-57.

Blanco Freijeiro, A. 1979: Historia de Sevilla. I (1) La ciudad antigua (De la Prehistoria a los Visigodos), Sevilla.

Blázquez, J. M. 1956: "Pinax fenicio con esfinge y árbol sagrado", Zephyrus 7 (2), 217-228.

Bonnet, C. 1987: “Typhon et Baal Șaphon”, E. Lipinski (ed.), Phoenicia and the east Mediterranean in the first millennium B.C., Leuven, 101-143.

Burillo, F. 2012: "El período del ibérico pleno en el territorio de los iberos del Ebro", M. C. Belarte, J A. Benavente, L. Fatás, J. Didoli, P. Moret y J. Noguera (eds.), Iberos del Ebro. Actas del II Congreso Internacional (Alcañiz-Tivissa, 16-19 de noviembre de 2011), Tarragona, 103-110.

Cárceles, E., Gallardo, J. y Ramos, F. 2011: "Excavaciones urbanas en Lorca: solar esquina calle Álamo con calle Núñez de Arce (santuario ibérico de tipo orientalizante)", Verdolay 13, 71-81.

Carriazo, J. M. 1970: El tesoro y las primeras excavaciones en "El Carambolo" (Camas, Sevilla), Madrid.

Carriazo, J. M. 1973: Tartesos y El Carambolo. Investigaciones arqueológicas sobre la Protohistoria de la Baja Andalucía, Madrid.

Celestino, S. 1994: "Los altares en forma de "lingote chipriota" de los santuarios de Cancho Roano", Revista de Estudios Ibéricos 1. La escultura ibérica, 291-310.

Celestino, S. 2008: "Los altares en forma de piel de toro de la Península Ibérica", J. J. Justel, J. P. Vita y J. Á. Zamora (eds.), Las culturas del Próximo Oriente Antiguo y su expansión mediterránea, Zaragoza, 321-348.

Celestino, S. y Salgado, J. A. 2007: "Fenicios e indígenas a través del Tesoro de Aliseda”, J. J. Justel, 
B. E. Solans, J. P. Vita y J. A. Zamora (eds.), Las aguas primigenias. El Próximo Oriente Antiguo como fuente de civilización. Actas del IV Congreso Español de Antiguo Oriente Próximo. Zaragoza, 587-601.

Conde, M., Izquierdo, R. y Escacena, J. L. 2005: "Dos escarabeos del santuario fenicio de Caura en su contexto histórico y arqueológico", Spal 14, 75-89. https://doi.org/10.12795/spal.2005.i14.03

Cornelius, I. 2004: The Many Faces of the Goddess. The Iconography of the Syro-Palestinian Goddesses Anat, Astarte, Quedeshet, and Asherah c. 1500-1000 BCE, Fribourg.

Counts, D. B. y Toumazou, M. K. 2006: "New Light on the Iconography of Bes in Archaic Cyprus", C. Mattusch, A. A. Donohue y A. Brauer (eds.), Common Ground: Archaeology, Art, Science, and Humanities. Proceedings of the XVIth International Congress of Classical Archaeology. Oxford, 598-602.

Dever, W. G. 1984: "Asherah, Consort of Yahweh? New Evidence from Kuntillet 'Ajrûd", Bulletin of the American Schools of Oriental Research 255, 21-37. https://doi.org/10.2307/1357073

Escacena, J. L. 2000: La arqueología protohistórica del sur de la Península Ibérica. Historia de un río revuelto, Madrid.

Escacena, J. L. 2001: "Fenicios a las puertas de Tartessos", Complutum 12, 73-96.

Escacena, J. L. 2002: "Dioses, Toros y Altares. Un templo para Baal en la antigua desembocadura del Guadalquivir", E. Ferrer (ed.): Ex Oriente Lux: Las religiones orientales antiguas en la Península Ibérica, Sevilla, 33-76.

Escacena, J. L. 2006: “Allas el estrellero, o Darwin en las sacristías", J. L. Escacena y E. Ferrer (eds.), Entre dios y los hombres: el sacerdocio en la Antigüedad, Sevilla, 103-156.

Escacena, J. L. 2007: "El dios que resucita: claves de un mito en su primer viaje a Occidente", J. J. Justel, J. P. Vita y J. Á. Zamora (eds.), Las culturas del Próximo Oriente Antiguo y su expansión mediterránea, Zaragoza, 615-651.

Escacena, J. L. 2011: "Variación identitaria entre los orientales de Tartessos. Reflexiones desde el antiesencialismo darwinista", M. Álvarez (ed.), Fenicios en Tartesos: nuevas perspectivas, Oxford, 161-192.

Escacena, J. L. 2013: "El espejismo tartésico", J. M. Campos y J. Alvar (eds.), Tarteso. El emporio del metal, Córdoba, 137-195.

Escacena, J. L. y Amores, F. 2011: "Revestidos como dios manda. El tesoro del Carambolo como ajuar de consagración”, Spal 20, 107-141. https://doi. org/10.12795/spal.2011.i20.08
Escacena, J. L. y Coto, M. 2010: “Altares para la eternidad", Spal 19, 149-185. https://doi.org/10.12795/ spal.2010.i19.07

Escacena, J. L. e Izquierdo, R. 2000: “Altares para Baal", Arys 3, 11-40.

Escacena, J. L. e Izquierdo, R. 2001: “Oriente en Occidente: arquitectura civil y religiosa en un 'barrio fenicio' de la Caura tartésica”, D. Ruiz y S. Celestino (eds.), Arquitectura oriental y orientalizante en la Península Ibérica, Madrid, 123-157.

Fernández Flores, A. y Rodríguez Azogue, A. 2005: "El complejo monumental del Carambolo Alto, Camas (Sevilla). Un santuario orientalizante en la paleodesembocadura del Guadalquivir", Trabajos de Prehistoria 62 (1), 111-138. https://doi. org/10.3989/tp.2005.v62.i1.58

Fernández Flores, A. y Rodríguez Azogue, A. 2007: Tartessos desvelado, Córdoba.

Fernández Gómez, F. 1997: Tesoros de la Antigüedad en el Valle del Guadalquivir, Sevilla.

Gallardo, J., Ramos, F., Cárceles, E. y Párraga, M. D. 2008: "Intervención arqueológica en calle Álamo esquina Núñez Arce, Lorca”, M. Lechuga, P. E. Collado y M. B. Sánchez (coords.), XIX Jornadas de Patrimonio Cultural de la Región de Murcia, vol. I. Cartagena, 283-286.

Garrido, J. P. y Orta, E. M. 1978: Excavaciones en la necrópolis de La Joya (Huelva) II $\left(3 .^{a}, 4 .^{a} y\right.$ 5. ${ }^{a}$ campañas), Madrid.

Gómez Lucas, D. 2002: "Introducción al dios Bes: de Oriente a Occidente", E. Ferrer (ed.), Ex Oriente Lux: Las religiones orientales antiguas en la Península Ibérica, Sevilla, 87-121.

Gómez Peña, A. 2010: “Así en Oriente como en Occidente: el origen oriental de los altares taurodérmicos de la Península Ibérica", Spal 19, 129-148. https://doi.org/10.12795/spal.2010.i19.06

Gómez Peña, A. 2011: "Nuevos datos sobre los altares taurodérmicos asirios y su simbología”, Lucentum XXX, 9-24. https://doi.org/10.14198/ lvcentvm2011.30.01

Gómez Peña, A. 2012-2013: "Historiografía y metodología taurodérmica: nuevas consideraciones sobre su simbolismo en la protohistoria peninsular ibérica", Anales de Arqueología Cordobesa 2324, 11-34.

Gómez Peña, A. 2017: La piel de toro como símbolo religioso e identitario en la colonización fenicio-púnica de la Península Ibérica desde una perspectiva darwinista, Sevilla, Tesis doctoral.

Gómez Peña, A. y Rodríguez, J. 2014: “A propósito de dos nuevos amuletos de Bes procedentes de Chipiona y Rota (Cádiz)", Spal 23, 147-165. https://doi.org/10.12795/spal.2014.i23.08 
Grup d’Investigació Prehistórica 2005: "Dos hogares orientalizantes de la fortaleza de Els Vilars (Arbeca, Lleida)", S. Celestino y J. Jiménez (eds.), El Período Orientalizante. Actas del III Simposio Internacional de Arqueología de Mérida: Protohistoria del Mediterráneo Occidental, Anejos de Archivo Español de Arqueología XXXV, vol. I, Mérida, 651-667.

Hadley, J. M. 2003: The Cult of Asherah in Ancient Israel and Judah. Evidence for a Hebrew Goddess, Cambridge.

Hermary, A. 1984: "Deux ex-voto chypriotes reconstitués", Revue du Louvre 34, 238-240.

Hermary, A. 1986: "Bes (Cypri et in Phoenicia)", Lexicon Iconographicum Mythologiae Classicae, vol. III, 1, Zürich, 108-112.

Keel, O. y Uehlinger, C. 1992: Göttinnen, Götter und Gottessymbole: Neue Erkenntnisse zur Religionsgeschichte Kanaans und Israels aufgrund bislang unerschlossener ikonographischer Quellen, Freiburg, Basel und Wien.

Kukahn, E. y Blanco, A. 1959: "El tesoro del Carambolo", Archivo Español de Arqueología XXXII, 38-49.

Lagarce, J. y Lagarce, E. 1997: "Les lingots «en peau de boeuf», objets de comerce et symboles idéologiques dans le monde méditerranéen", Reppal X, 73-97.

Lemaire, A. 1984: "Date et origine des inscriptions hebraiques et pheniciennes de Kuntillet 'Ajrud", Studi Epigrafici e Linguistici 1, 133-143.

López Pardo, F. 2006: La torre de las almas: un recorrido por los mitos y creencias del mundo fenicio y orientalizante a través del monumento de Pozo Moro, Madrid.

Maier, J. 2003: "El lingote en rama chipriota o de piel de toro: símbolo divino de la antigua Iberia", A. García-Baquero y P. Romero (eds.), Fiestas de toros y sociedad, Sevilla, 85-106.

Maluquer, J. 1958: "Nuevos hallazgos en el área tartésica", Zephyrus IX, 201-219.

Maluquer, J. 1984 [1970]: Tartessos. La ciudad sin Historia, Barcelona.

Marín, M. C. 2006: "De dioses, pieles y lingotes", Habis 37, 35-54.

Merlo, P. 1998: La dea Ašratum - Atiratu - Ašhera. Un contributo alla storia della religione semítica del Nord, Roma.

Meshel, Z. 1978: Kuntillet 'Ajrud: A Religious Centre from the Time of the Judaean Monarchy on the Border of Sinai, Jerusalem.

Mettinger, T. N. D. 1995: No Graven Image? Israelite Aniconism in Its Ancient Near Eastern Context, Stockholm.
Nicolini, G. 1990: Techniques des ors antiques. La bijouterie ibérique du VIIe au IVe siècle, 2 vols, Paris.

Padilla, A. 1993: "Caura: el topónimo", J. L. Escacena (coord.), Arqueología de Coria del Río y su entorno, Coria del Río, 63-64.

Pavón, I., Rodríguez Díaz, A. y Duque, D. M. 2017: "El tesoro de Aliseda: de la «historia oficial» a la intrahistoria”, A. Rodríguez Díaz, I. Pavón y D. M. Duque (eds.), Historias de Tesoros. Tesoros con Historia, Cáceres, 241-275.

Perea, A. 2006: "Entre la metáfora y el mito. La representación simbólica de lo femenino en la sociedad ibérica", MARQ, Arqueología y Museos 1, 49-68.

Perea, A. 2007: "Las joyas de la Dama de Baza: un espacio femenino", T. Chapa e I. Izquierdo (coords.), La Dama de Baza. Un viaje femenino al más allá, Madrid, 201-209.

Pesce, G. 1965: Le statuette puniche di Bithia, Roma. Rafel, N., Montero-Ruiz, I., Catanyer, P., Aquilué, X., Armada, X. L., Belarte, M. C., Fairén, S., Gasull, P., Gener, M., Graells, R., Hunt, M., Martín, A., Mata, J. M., Morell, N., Pérez, A., Pons, E., Renzi, M., Rovira, M. C., Rovira, S., Santos, M., Tremoleda, J. y Villalba, P. 2010: "New Approaches on the Archaic Trade in the North-Eastearn Iberian Peninsula: Exploitation and Circulation of Lead and Silver", Oxford Journal of Archaeology 29 (2), 175-202. https://doi.org/10.1111/j.14680092.2010.00344.x

Rodríguez Díaz, A., Ortiz, P., Pavón, I. y Duque, D. M. 2014: El tiempo del tesoro de Aliseda, I. Historia e historiografía del hallazgo, Mérida.

Rodríguez Díaz, A., Pavón, I y Duque, D. M. 2017: "Aproximación al contexto de las joyas de Aliseda: reinventando la tradición”, A. Rodríguez Díaz, I. Pavón y D. M. Duque (eds.), Historias de Tesoros. Tesoros con Historia. Cáceres, 277-318.

Sanmartí, J., Asensio, D., Miró, M. T. y Jornet, R. 2012: "El Castellet de Banyoles (Tivissa): Una ciudad ibérica en el curso inferior del río Ebro", Archivo Español de Arqueología 85, 43-63. https:// doi.org/10.3989/aespa.085.012.003

Schmidt, B. B. 2016: The Materiality of Power: Explorations in the Social History of Early Israelite Magic, Tübingen.

Seco, I. 2010: Piedras con Alma. El Betilismo en el Mundo Antiguo y sus manifestaciones en la Península Ibérica, Sevilla.

Shaw, J. W. (1989): "Phoenicians in Southern Crete", American Journal of Archaeology 93, 165-183. https://doi.org/10.2307/505085

Stoltz, F. 1980: "Monotheismus in Israel”, O. Keel (ed.), Monotheismus im alten Israel und seiner Umwelt, Fribourg, 143-184. 
Tejera, A. y Fernández, J. 2012: Los dioses de los tartesios, Barcelona.

Tito, V. 2012: “Zeus Kasios. Un culto montano a tutela della navigazione", Tradizione, Tecnologia e territorio, vol. I, Roma, 81-105.

Torres, M. 2002: Tartessos, Madrid.

Tran Tam Tinh, V. 1986: "Bes”, Lexicon Iconographicum Mythologiae Classicae, vol. III, 1, Zürich, 98-108.

Tzavellas-Bonnet, C. 1985: "Melqart, Bès et l'Héraclès Dactyle de Crète", E. Lipiński y E. Gubel (eds.), Phoenicia and its neighbours, Leuven, 231-240.

Vázquez Hoys, A. M. 2006: "Una hipótesis sobre la posible relación entre las operadoras cultuales femeninas en la Península Ibérica en época prerromana. Los altares en forma de lingote / piel de toro y las serpientes", Rivista di Studi Fenici XXXIV, 1, 97-114.

Velázquez, F. 2007: El dios Bes: de Egipto a Ibiza, Ibiza.

Yon, M. 1986: “Cultes phéniciens à Chypre: l'interprétation chypriote", C. Bonnet, E. Lipiński y P. Marchetti (ed.), Religio Phoenicia, Brussels, 127-152.

Recibido: 10-11-2016

Aceptado: 01-10-2017 